\title{
Article \\ Unraveling Protein Interactions between the Temperate Virus Bam 35 and Its Bacillus Host Using an Integrative Yeast Two Hybrid-High Throughput Sequencing Approach
}

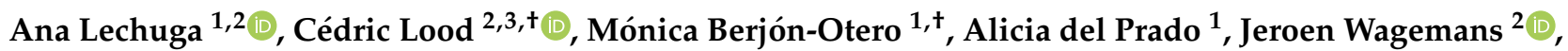 \\ Vera van Noort ${ }^{3}$, Rob Lavigne ${ }^{2}\left(\mathbb{D}\right.$, Margarita Salas ${ }^{1, \mp(1)}$ and Modesto Redrejo-Rodríguez ${ }^{1,4, * \mathbb{C}}$ \\ 1 Centro de Biología Molecular Severo Ochoa (CSIC-UAM), 28049 Madrid, Spain; ana.lechuga@kuleuven.be (A.L.); \\ monicaberjon@hotmail.com (M.B.-O.); a.delprado@csic.es (A.d.P.); msalas@cbm.csic.es (M.S.) \\ 2 Laboratory of Gene Technology, Department of Biosystems, KU Leuven, 3001 Leuven, Belgium; \\ cedric.lood@kuleuven.be (C.L.); jeroen.wagemans@kuleuven.be (J.W.); rob.lavigne@kuleuven.be (R.L.) \\ 3 Centre of Microbial and Plant Genetics, Laboratory of Computational Systems Biology, Department of \\ Microbial and Molecular Systems, KU Leuven, 3001 Leuven, Belgium; vera.vannoort@kuleuven.be \\ 4 Departamento de Bioquímica, Universidad Autónoma de Madrid (UAM) and Instituto de Investigaciones \\ Biomédicas Alberto Sols (CSIC-UAM), 28029 Madrid, Spain \\ * Correspondence: modesto.redrejo@uam.es; Tel.: +34-914975963 \\ $\dagger$ Contributed equally to this work. \\ $\ddagger$ Deceased.
}

Citation: Lechuga, A.; Lood, C.; Berjón-Otero, M.; del Prado, A.; Wagemans, J.; van Noort, V.; Lavigne, R.; Salas, M.; Redrejo-Rodríguez, M Unraveling Protein Interactions between the Temperate Virus Bam35 and Its Bacillus Host Using an Integrative Yeast Two Hybrid-High Throughput Sequencing Approach. Int J. Mol. Sci. 2021, 22, 11105. https:// doi.org/10.3390/ijms222011105

Academic Editor: Alicja Wegrzyn

Received: 27 August 2021

Accepted: 10 October 2021

Published: 14 October 202

Publisher's Note: MDPI stays neutral with regard to jurisdictional claims in published maps and institutional affiliations.

Copyright: (c) 2021 by the authors Licensee MDPI, Basel, Switzerland This article is an open access article distributed under the terms and conditions of the Creative Commons Attribution (CC BY) license (https:// creativecommons.org/licenses/by/ $4.0 /)$
Abstract: Bacillus virus Bam35 is the model Betatectivirus and member of the family Tectiviridae, which is composed of tailless, icosahedral, and membrane-containing bacteriophages. Interest in these viruses has greatly increased in recent years as they are thought to be an evolutionary link between diverse groups of prokaryotic and eukaryotic viruses. Additionally, betatectiviruses infect bacteria of the Bacillus cereus group, which are known for their applications in industry and notorious since it contains many pathogens. Here, we present the first protein-protein interactions (PPIs) network for a tectivirus-host system by studying the Bam35-Bacillus thuringiensis model using a novel approach that integrates the traditional yeast two-hybrid system and high-throughput sequencing (Y2H-HTS). We generated and thoroughly analyzed a genomic library of Bam35's host B. thuringiensis HER1410 and screened interactions with all the viral proteins using different combinations of bait-prey couples. Initial analysis of the raw data enabled the identification of over 4000 candidate interactions, which were sequentially filtered to produce 182 high-confidence interactions that were defined as part of the core virus-host interactome. Overall, host metabolism proteins and peptidases were particularly enriched within the detected interactions, distinguishing this host-phage system from the other reported host-phage PPIs. Our approach also suggested biological roles for several Bam35 proteins of unknown function, including the membrane structural protein P25, which may be a viral hub with a role in host membrane modification during viral particle morphogenesis. This work resulted in a better understanding of the Bam35-B. thuringiensis interaction at the molecular level and holds great potential for the generalization of the Y2H-HTS approach for other virus-host models.

Keywords: Bam35; tectivirus; Betatectivirus; interactome; yeast two-hybrid; Bacillus thuringiensis; protein-protein interactions; high-throughput sequencing

\section{Introduction}

The family Tectiviridae is defined as a family of tailless, icosahedral viruses with a lipidic inner membrane and a linear, double-stranded DNA genome of approximately $15 \mathrm{~kb}$, which is capped by the so-called terminal protein [1]. These phages are currently divided into five genera, encompassing lytic and lysogenic bacteriophages that infect Gram-negative or Gram-positive bacteria, respectively. The early and best-known lytic viruses that prey on Gram-negative bacteria belong to the Alphatectivirus genus, whereas the temperate 
phages infecting Gram-positive bacteria were grouped in the Betatectivirus genus, and the recently reported new members of the family were assigned to the Gamma-, Delta-, and Epsilontectivirus genera [2]. This family spans a wide genetic diversity under a common morphology with a broad host range and a predicted significant ecological importance [3,4]. Additionally, they were proposed to be related to the origin of some mobile elements and groups of eukaryotic DNA viruses [5,6]. Among the Tectiviridae members, the interest in betatectiviruses has increased in the last decade due to their ability to infect different members of the Bacillus cereus group [7]. Indeed, some specifically infect pathogenic bacteria, such as phages Wip1 and AP50, can infect Bacillus anthracis, which is the etiological agent of anthrax [8,9], or Sole and Simila, which infects the food pathogen B. cereus [10].

The model virus for molecular and structural studies on betatectiviruses is Bacillus virus Bam35 [11-14]. This phage infects Bacillus thuringiensis, which is a type species of the $B$. cereus group that is known for its entomocidal capacity and is broadly used as biopesticide for pest control $[15,16]$. The betatectivirus genome organization is modular and traditionally segmented into three functional categories (Supplementary Figure S1): (i) gene regulation and genome replication, (ii) virion structure and DNA packaging, and (iii) host recognition and cell lysis [17]. Despite the conserved genome organization between Bam35 and the widely characterized model virus for Alphatectivirus phage PRD1, there is a very low sequence identity between them. Moreover, the limited similarity to proteins that are published in databases hinders the functional annotation of Bam 35 and other tectiviruses. This problem was addressed by comparative studies, single protein purification and analysis, and protein-protein interaction (PPI) studies, resulting in the current functional annotation of 23 out of the 32 open reading frames of Bam35 [11,13,18,19].

The icosahedral capsid of Bam35 is mainly composed of the major capsid proteins that form the facets, and the penton proteins that are located in the eleven vertices and incorporate the flexible spikes. Packaging and injection of DNA take place through the 12th vertex, which is also known as the special vertex [12]. Both capsid proteins and dsDNA interact with inner membrane lipids [12,20]. Although not all membrane proteins have been identified for Bam35, P25 is probably a membrane structural component and P26 is a conserved transglycosylase that seems to be a cornerstone transmembrane protein that interacts with both lytic and capsid proteins $[19,21]$.

Bam35 was proposed to infect host cells following a three-step mechanism. First, the flexible spikes recognize and bind the cell surface receptor. So far, only one of the components of this receptor has been identified, namely, the N-acetyl-muramic acid, which is essential for phage adsorption [22]. Second, the peptidoglycan hydrolyzing proteins facilitate overcoming the cell wall barrier to access the plasma membrane. Finally, as in PRD1, Bam35 forms a tail-like structure that consists of a proteo-lipidic tube that protrudes from the inner lipid membrane and delivers the linear dsDNA into the cell $[12,22,23]$. The Bam 35 genome is replicated by a protein-primed mechanism that uses a terminal protein (TP) to prime the genome replication and thus remains linked to the $5^{\prime}$ DNA ends $[13,24,25]$. Upon infection of the cell, this temperate phage can establish a lysogenic state as a linear episome. The lysis-lysogeny switch was studied regarding the GIL01 virus, which is almost identical to Bam35 [26]. During lysogeny, the host transcription repressor LexA remains bound to viral protein P7 and restricts the transcription of the late genes $[18,27,28]$. However, only low-expression levels were suggested for all viral genes during the GIL01/Bam35 temperate phase. Nonetheless, the phage impacts bacterial growth, sporulation, motility, and biofilm formation [29]. Host cell activation of the SOS response allows the phage to enter the lytic cycle, which is mediated by the elimination of transcription repression and transcription activation of the late genes by the viral protein P6 [30]. In a final step during the lytic cycle, Bam35 virions are released via lysis, likely through an endolysin-holin system [31]. Although two endolysins were described (P26 and P30), no holin has been identified to date [21].

The protein intraviral interactome of Bam35, as well as of other viruses, recently revealed new functions and the localization of phage ORFan proteins [19]. However, 
understanding host-virus PPIs is also essential for studying protein functions, life cycle, and evolution, and is particularly helpful for identifying molecular targets to combat pathogens [32]. The last decade has seen the emergence of "omics" approaches as investigative tools for the study of biological pathways that are involved in pathogen replication, host response, and, eventually, infection progression. Among the methods that are used in high-throughput interactomics, the yeast two-hybrid system $(\mathrm{Y} 2 \mathrm{H})$ remains one of the most widely used techniques for studying PPIs [33]. Some of the first $\mathrm{Y} 2 \mathrm{H}$ studies involving viruses addressed the interaction between bacteria and their phages. These included Escherichia coli phages T7 and $\lambda$, Pseudomonas aeruginosa phages, Streptococcus pneumoniae phages Cp-1 and Dp-1, and mycobacteriophage Giles [34-39]. Other techniques for detecting PPIs, such as affinity purification coupled to mass spectrometry, also significantly contributed to the study of phage-bacteria interactions [40,41]. These works suggest different and specialized PPI networks, reflecting their genetic diversity, distinct biology, and diverging co-evolution with their specific hosts [42]. Despite phage-host specialization, proteins of phages infecting the same host are suggested to employ similar strategies. All of them appear to share a tendency to interact with central "hub" proteins, highlighting their potential disruptive effect on the host metabolism. Another commonality is found in the targeting of proteins involved in transcription, replication, recombination, and repair functions [38].

The recent combination of $\mathrm{Y} 2 \mathrm{H}$ with high-throughput sequencing technologies (HTS) overcomes labor-intensive clone-by-clone analysis and has been shown to speed up the study of PPIs while increasing the efficiency and sensitivity of the method. Different approaches were implemented, including recombination-based methods [43-45] and methods based on genomic library screening against one single protein $[46,47]$. Although these techniques represent a marked improvement of the method, the data analysis and interpretation remain a challenge. Indeed, the large amounts of data generated with these approaches require the development of specific bioinformatics pipelines, and fine-tuning of thresholds to select reliable interactions.

To date, few large-scale analyses of phage-bacteria PPIs have been conducted. These works focus on model viruses from the order Caudovirales [35-39] and, to our knowledge, no detailed studies on phage-host PPIs have been performed on other groups of phages, including the family Tectiviridae. Besides, these existing studies rely on $\mathrm{Y} 2 \mathrm{H}$ screens of individual clones. In our work, we used a novel yeast two-hybrid-high-throughput sequencing approach (Y2H-HTS), aiming to obtain a proteome-wide virus-host protein interactome between the betatectivirus Bam 35 and its host, namely, B. thuringiensis. By performing a total of $156 \mathrm{Y} 2 \mathrm{H}$ assays, we established a highly selective interactome Bam35$B$. thuringiensis in which we could detect patterns within the phage-host interactions and identify specific interactions to better understand viral protein functions and phage biology.

\section{Results}

2.1. Integrating the Yeast Two-Hybrid System with high-throughput Sequencing for High-Confidence Interaction Datasets

To obtain an extensive protein-protein interactome of Bam 35 and B. thuringiensis by developing a novel and customizable approach, we established an experimental setup that combined traditional yeast two-hybrid with high-throughput sequencing methods (hereafter Y2H-HTS). We used the previously generated Bam35 ORF collection [19], containing bait constructs for all 32 ORFs of Bam35, which were cloned in both orientations (C- and $\mathrm{N}$-terminal fusions to the Gal4p DNA binding domain (DBD)). This collection also includes truncated versions of proteins (labeled with a " $\mathrm{t}$ ") with a predicted transmembrane domain, from which this domain was removed. The Bam 35 ORF constructs were used to screen two newly generated genomic libraries of $B$. thuringiensis.

The genomic libraries of the Bacillus thuringiensis HER1410 genome $(6,147,475 \mathrm{bp})$ that is suitable for $\mathrm{Y} 2 \mathrm{H}$ were obtained using a four-step procedure (Figure 1). These libraries were generated via the partial digestion of the genomic DNA followed by insertion of the obtained fragments into the $\mathrm{Y} 2 \mathrm{H}$ prey expression vectors pGADCg and pGADT7g (pPC 
and $\mathrm{pPN}$ ), respectively generating $\mathrm{C}$-terminal and $\mathrm{N}$-terminal fusions of DNA-binding Gal4p activation domain (AD) to the Gateway cassette.

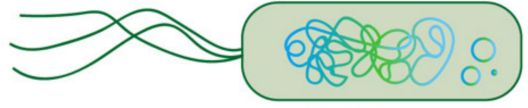

B. thuringiensis HER1410

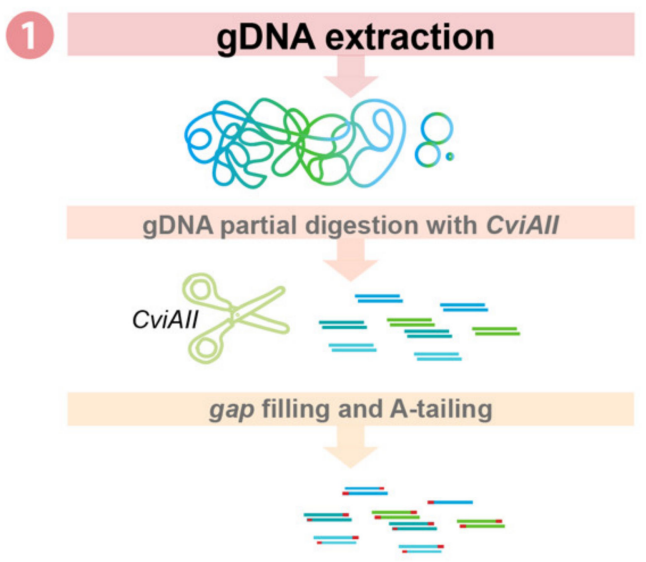

Library cloning into PCRTM8/GW/TOPO®

Library in pCR8/GW/TOPO

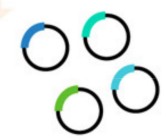

\section{E. coli TOP10 transformation}

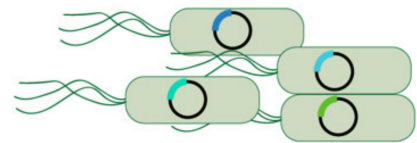

235,620 E. coli TOP10 CFU Library propagation

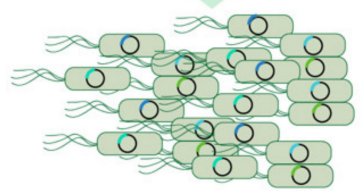

$6.6 \times 10^{8}$ E. coli TOP10 CFU/mL Plasmidic DNA extraction

Library in PCR8/GW/TOPO

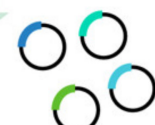

\section{Library subcloning into prey vectors}

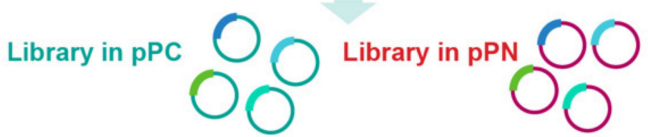

E. coli TOP10 transformation

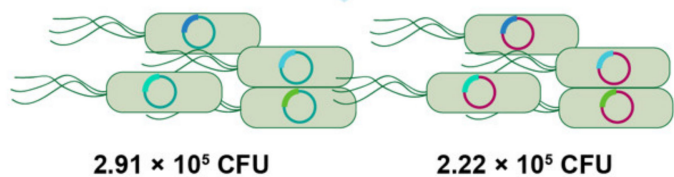

Libraries propagation

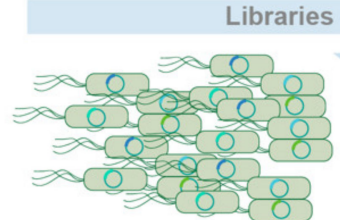

$1 \times 10^{9} \mathrm{CFU} / \mathrm{mL}$

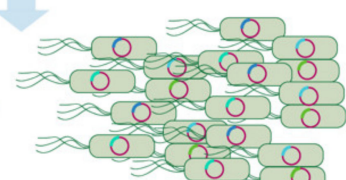

Plasmidic DNA extraction

Library in pPC
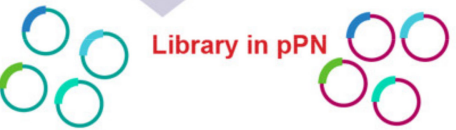

\section{S. cerevisiae Y187 transformation}
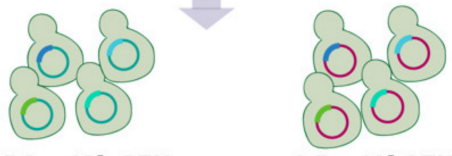

$5.9 \times 10^{5} \mathrm{CFU}$

$6.5 \times 10^{5} \mathrm{CFU}$ Libraries propagation
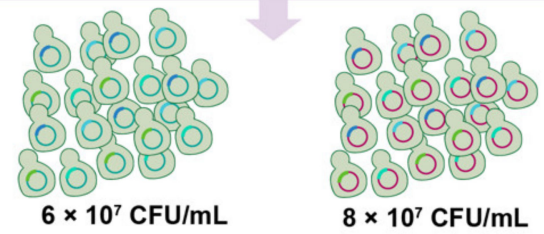

Library fragments PCR amplification
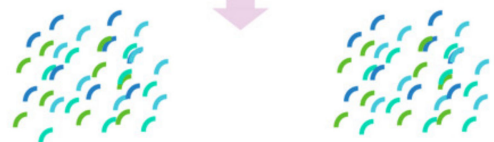

Libraries sequencing

Figure 1. Y2H genomic library construction workflow. (1) The genomic DNA of B. thuringiensis HER1410 (blue-green) was partially digested using CviAII and cloned into the pCRTM8/GW/TOPO vector (black circles), generating the HER1410 genomic library in pCRTM8/GW/TOPO. (2) This library was used to transform Escherichia coli TOP10 cells that were propagated and used for plasmid extraction. (3) The library in pCRTM8/GW/TOPO was subcloned into the Y2H prey vectors PPC (teal circles, DNA-binding Gal4p activation domain (AD) fused at the C-terminus of the genomic fragment) and pPN (red circles, AD fused at the N-terminus), generating genomic libraries in $\mathrm{PPC}$ and pPN. After the transformation, propagation, and plasmid DNA extraction, both libraries were used to transform S. cerevisiae Y187 (4). Libraries in S. cerevisiae were propagated, plasmid-extracted, PCR-amplified, and sequenced using Illumina HTS (5, see below and Figure 2). The number of independent clones for each transformation step is indicated. 


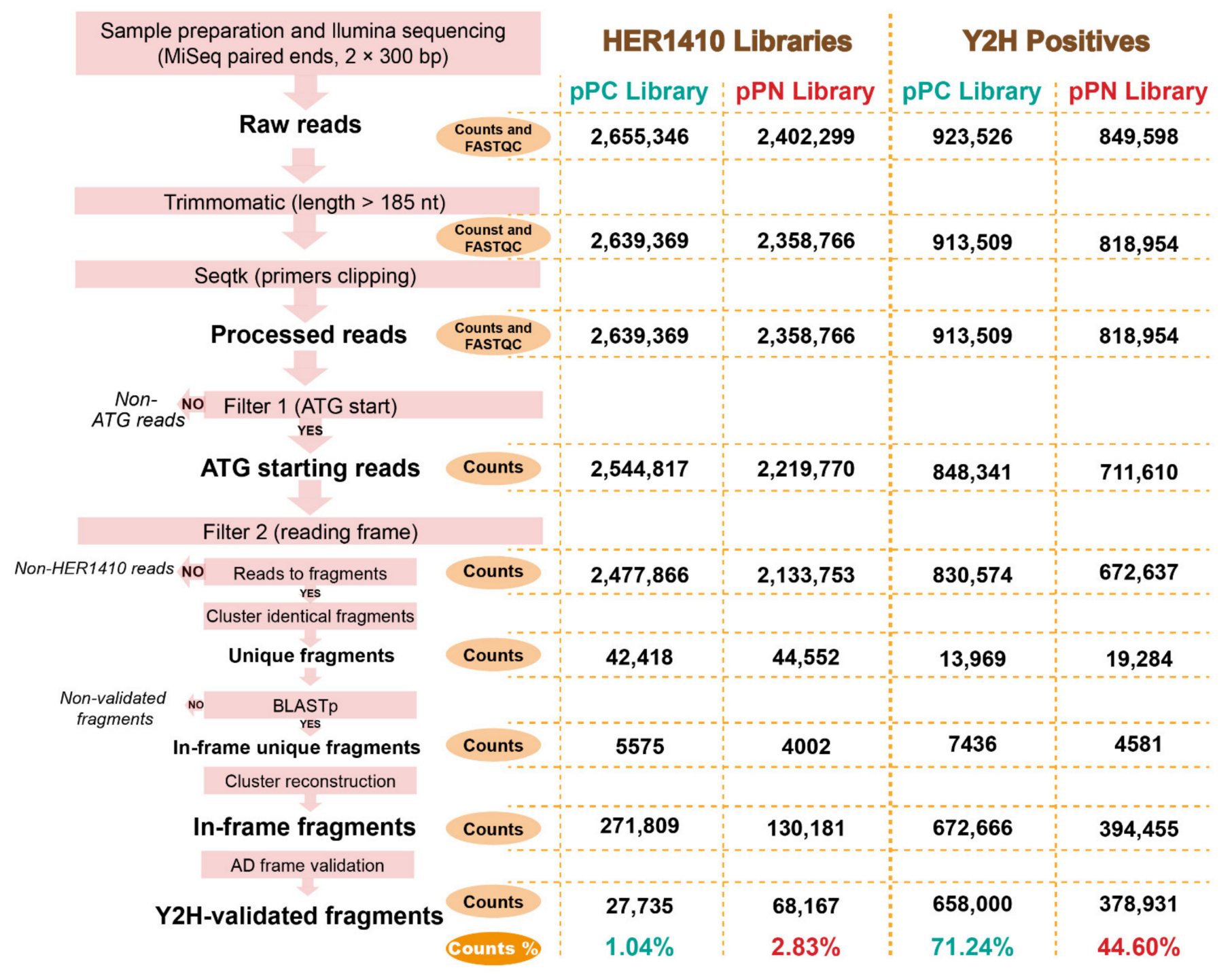

Figure 2. Analysis of the high-throughput sequencing data from the B. thuringiensis HER1410 genomic libraries and $\mathrm{Y} 2 \mathrm{H}$ positive hits. Bioinformatics pipeline for the Y2H-HTS data analysis. Schematic representation of the different steps that were followed for sequencing the data processing of $\mathrm{Y} 2 \mathrm{H}$ libraries and $\mathrm{Y} 2 \mathrm{H}$ positives. After each step, the number of reads or fragments was calculated (counts). For each library, these counts are indicated in the two columns on the right (pPC: teal, pPN: red). For the Y2H positives, only the reads over $300 \mathrm{bp}$ are detailed, see Supplementary Figure S9 for the complete analysis. The final percentage of validated reads is indicated. In the first few steps, FastQC was used to evaluate the quality of the reads, as illustrated in Supplementary Figure S3.

Both libraries were analyzed in detail using Illumina sequencing. A custom bioinformatics pipeline (Figure 2) was generated to process the HTS data of the HER1410 libraries, as well as the yeast two-hybrid positive hits (see below). Regarding the $\mathrm{Y} 2 \mathrm{H}$ libraries, selected fragments of the libraries containing ATG-starting reads (97\% for pPC and $96 \%$ for $\mathrm{pPN}$ ) were converted into HER1410 fragments that, after clustering, yielded at least 40,000 different HER1410 fragments for each library. Mapping of these unique fragments against the host genome resulted in a coverage of $40 \%$ of the total nucleotides of HER1410, which was almost identical for both libraries (40.8\% for pPC and 40.07\% for $\mathrm{pPN})$. Furthermore, both libraries were equally distributed throughout the genome with similar coverage (Supplementary Figure S2). Two additional filters were applied to the unique fragments based on their translation and position relative to the GAL4-AD gene (the GAL4p activation domain-encoding part). The final $\mathrm{Y} 2 \mathrm{H}$-validated fragments represented a total of 417 genes of HER1410 (7.2\%) in the pPC and 781 genes (13.5\%) in the pPN library 
(Supplementary Table S1). Although both libraries initially contained a similar distribution of ATG fragments, the difference in the number of validated genes represented by each library, which was lower for pPC, was mainly due to the differential final filtering step, which was more stringent for this combination (see the Materials and Methods section).

The interaction analysis of all viral ORFs against the genomic library in both orientations resulted in a total of 158 different possible combinations (Figure 3), including control mating experiments of our libraries with the empty bait vectors. However, given that the ORF16 of Bam35 was not available in the PPC vector [19], this number was reduced to 156 individual $\mathrm{Y} 2 \mathrm{H}$ assays. For each assay, a bait yeast harboring the Bam $35 \mathrm{ORF}(\mathrm{X})$ bait expression vector was mated with one of the prey libraries. The overall calculated mating efficiency was $61.23 \%$.

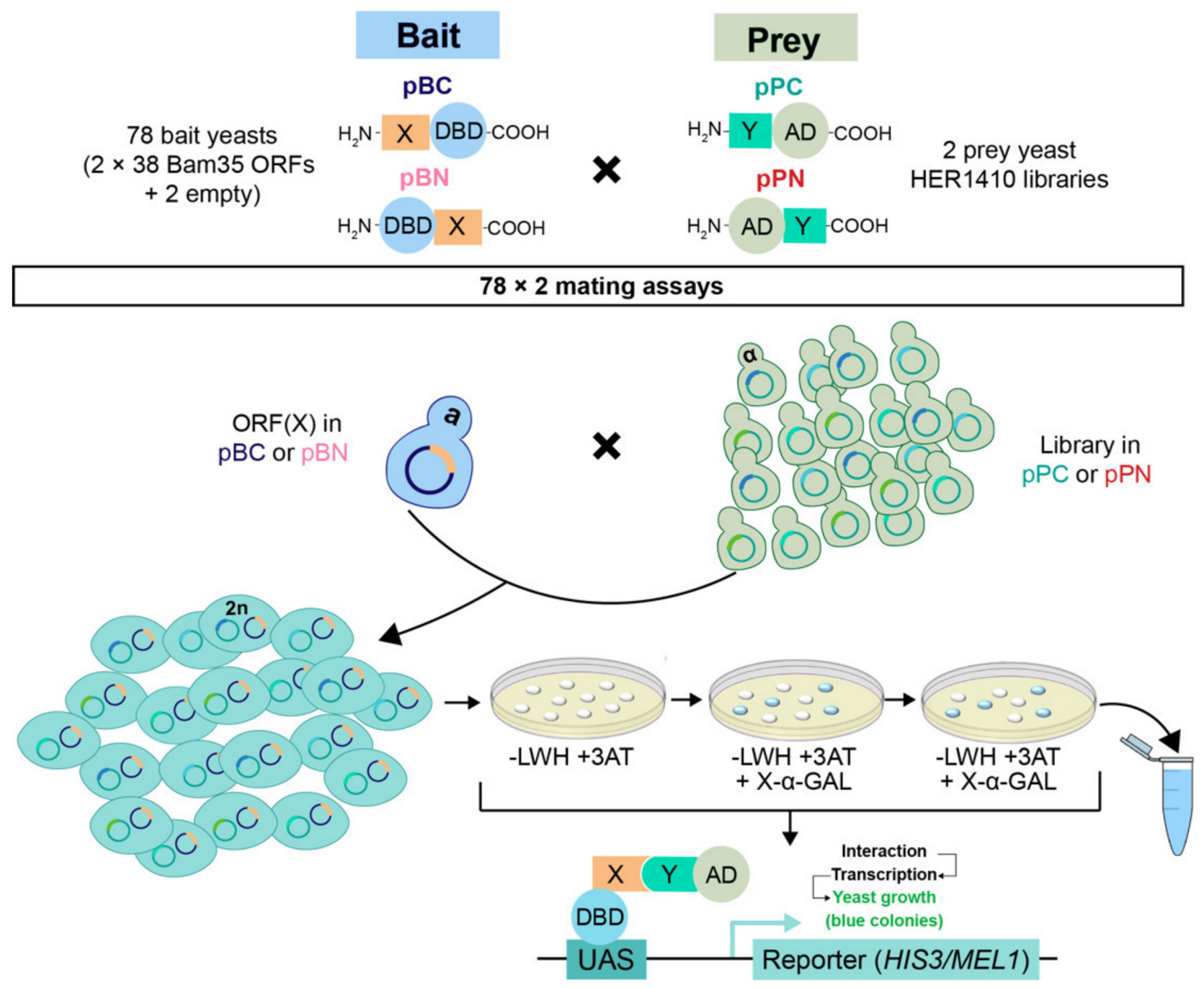

Figure 3. Bam35-B. thuringiensis $\mathrm{Y} 2 \mathrm{H}$ interactome screening. Schematic representation of the $\mathrm{Y} 2 \mathrm{H}$ assays. A total of $156 \mathrm{Y} 2 \mathrm{H}$ experiments were performed to test the interactions between each of the ORFs of Bam35 (X) that were cloned into bait vectors (C- and N-terminal fusion) and the generated HER1410 libraries ( $\mathrm{Y}$ ) that were cloned into prey vectors (C- and N-terminal fusion). For each assay, a Bam35 ORF-containing bait yeast was mated with one of the HER1410 library-containing prey yeast. Positive interactions were detected using HIS3 and MEL1 markers. Mated cells were plated on selective solid media without leucine, tryptophan, or histidine (-LWH); supplemented with the corresponding 3AT concentration; and then replicated twice in -LWH +3AT plates supplemented with X- $\alpha$-Gal. The cells that were able to express the HIS3 gene grew on -LWH plates and, further, those that were able to express MEL1 turned blue in presence of $\mathrm{X}-\alpha-\mathrm{Gal}$. All cells of the last replica were pooled and harvested for further analysis. 
Positive interactions were first detected using the HIS3 reporter gene by plating the mated cells on selective media lacking histidine (Figure 3 and Supplementary Figure S4A). To increase the stringency of selection when using the HIS3 reporter gene, autoactivation of the bait proteins was minimized by adding the optimal concentration of the inhibitor 3-amino-1,2,4-triazole (3AT) for each bait construct. Furthermore, the reduction in cell background and, therefore, the efficient growth and selection of positive colonies was achieved via two steps of replica plating (Supplementary Figure S4A). As can be observed in Supplementary Figure S4A, the screening led to a wide variety of results in terms of color and number of colonies. The assays that included the pPN library were plated on selective media with low 3AT concentrations $(0-0.1 \mathrm{mM}$ ) resulted in a pink lawn (Supplementary Figure S4A, lane 4). This could correspond to a false positive background caused by the pPN library, which prevented the recovery of positive colonies. For these cases, the increase in $3 \mathrm{AT}$ concentration up to $3 \mathrm{mM}$ effectively prevented the pink lawn, enabling the growth of previously hidden interacting partners (lane 5). In addition, based on the MEL1 reporter selection system, 5 -bromo-4-chloro-3-indolyl $\alpha$-D-galactopyranoside (X- $\alpha$-Gal) was added to identify and amplify reliable interactions by increasing the 3AT concentration in the plates containing mostly white colonies (weak interaction). However, the plates meeting this requirement already contained the highest concentration of 3AT. To identify the prey interaction partners in each assay, cells from the last replica plate ( $\mathrm{Y} 2 \mathrm{H}$ positive clones) were pool-harvested and the prey fragments were amplified using PCR for subsequent Illumina sequencing (Supplementary Figure S4B). The PCR products of each assay showed distinct patterns of discrete bands or a smear, which corresponded to different sizes within the library size range. Nine combinations showed few or no colonies and, consequently, no PCR product was generated (Supplementary Table S2).

High-throughput analysis of each $\mathrm{Y} 2 \mathrm{H}$ assay using Illumina sequencing (300 bp paired-end run) resulted in 12,229 reads per sample on average (Supplementary Table S2). These reads were filtered using the bioinformatics pipeline illustrated in Figure 2. After the data treatment, mapping of the $\mathrm{Y} 2 \mathrm{H}$-validated fragments allowed us to retrieve a total of 4477 possible interactions (Table 1, Supplementary Table S3). A detailed analysis of these results, as described in the Supplementary Material, revealed that the $\mathrm{Y} 2 \mathrm{H}$ screening strongly favored fragments in the frame with the GAL4-AD gene and the actual ORFs within the genome. Only a minor library-borne background was observed, primarily for combinations that included the pPN library. The 4477 interactions were classified according to their enrichment or presence in the Illumina reads dataset as follows: A (100-10\% of normalized counts), B (10-0.25\%), and C $(0.25-0 \%)$. These categories were validated via a small-scale sequencing analysis, which showed a $100 \%$ recovery of prey fragments by HTS (except for IS4 transposases) and a good correlation between their presence in the sample and their enrichment category (see the Supplementary Material for details).

Table 1. Frequency of interactions for each enrichment category. The table shows the total number of interactions and the proportion of sequencing reads (counts) that fell into each enrichment category (A for prey proteins detected as 10-100\% of the sample counts, B for $0.25-10 \%$, and C for $0-0.25 \%$ ).

\begin{tabular}{|c|c|c|c|c|c|c|c|c|c|c|c|}
\hline \multirow{2}{*}{\multicolumn{2}{|c|}{ Enrichment }} & \multicolumn{5}{|c|}{ Number of Interactions } & \multicolumn{5}{|c|}{ Read Counts (\%) } \\
\hline & & \multicolumn{2}{|c|}{$p B C$} & \multicolumn{2}{|c|}{$p B N$} & \multirow[b]{2}{*}{ Total } & \multicolumn{2}{|c|}{$p B C$} & \multicolumn{2}{|c|}{$p B N$} & \multirow[b]{2}{*}{ Total } \\
\hline Category & Range & $\begin{array}{c}\text { pPC } \\
\text { Library }\end{array}$ & $\begin{array}{c}\text { pPN } \\
\text { Library }\end{array}$ & $\begin{array}{c}\text { pPC } \\
\text { Library }\end{array}$ & $\begin{array}{c}\text { pPN } \\
\text { Library }\end{array}$ & & $\begin{array}{c}\text { pPC } \\
\text { Library }\end{array}$ & $\begin{array}{c}\text { pPN } \\
\text { Library }\end{array}$ & $\begin{array}{c}\text { pPC } \\
\text { Library }\end{array}$ & $\begin{array}{c}\text { pPN } \\
\text { Library }\end{array}$ & \\
\hline $\mathbf{A}$ & $10-100 \%$ & 93 & 43 & 67 & 27 & 230 & 77.89 & 72.61 & 73.75 & 81.09 & 75.93 \\
\hline B & $0.25-10 \%$ & 262 & 165 & 391 & 95 & 913 & 20.76 & 24.34 & 24.52 & 15.76 & 22.03 \\
\hline $\mathrm{C}$ & $0-0.25 \%$ & 738 & 794 & 990 & 812 & 3334 & 1.35 & 3.05 & 1.73 & 3.15 & 2.04 \\
\hline Total & & 1093 & 1002 & 1448 & 934 & 4477 & 100 & 100 & 100 & 100 & 100 \\
\hline
\end{tabular}


A similar number of total interactions, around 1000, were found for each of the baitprey combinations $\mathrm{CC}, \mathrm{CN}$, and $\mathrm{NN}$ ( $\mathrm{pBC}-\mathrm{pPC}, \mathrm{pBC}-\mathrm{pPN}$, and $\mathrm{pBN}-\mathrm{pPN}$, respectively), although their distribution into categories varied. Indeed, the major contributor to the category A interactions was the CC combination, while the $\mathrm{NN}$ combination generated the lowest number of A interactions. On the other hand, the NC ( $\mathrm{pBN}-\mathrm{pPC}$ ) combination resulted in at least one third more interactions than the other combinations, contributing more to B and C total interactions, but similarly to category A. Overall, compared with the pPC library interactions, those involving the pPN library showed a higher percentage of reads in category $\mathrm{C}$.

Remarkably, although a total of 3334 interactions out of the 4477 were grouped in category C, they corresponded to only $2.04 \%$ of the total reads (Table 1 ). These hits could not be properly discriminated from the data noise (see the Supplementary Material) and were excluded from the main results to increase the specificity, resulting in a dataset of 1143 interactions (Table 2). This is consistent with $\mathrm{Y} 2 \mathrm{H}$ methods sometimes having a high rate of false positives [48]. In addition to the use of the appropriate 3AT concentration to prevent autoactivation by baits, two data filters were used to remove false positives. First, potential "sticky" preys, i.e., promiscuous prey fragments that interact with more than the average number of different bait interactors (six), were identified. A total of 36 "sticky" prey (Supplementary Table S4) were removed, reducing the dataset to a total of 228 filtered interactions (Table 2). Second, the prey CDS fragments that were identified in diploid yeast harboring the empty plasmid (Supplementary Table S5) were also tagged as false positives and deleted from the dataset. Due to their tag as "sticky" prey, most of the prey fragments detected in the empty combinations had already been removed with the previous filter. Therefore, this second filtering step resulted in a reduction of only 17 hits.

Table 2. Total number of interactions detected by the $\mathrm{Y} 2 \mathrm{H}$ screening after each filtering step.

\begin{tabular}{cccccc}
\hline Combination & Total & A + B Categories & No “Sticky” Prey & No Empty & No Duplicates \\
\hline$p B C-p P C$ Library & 1093 & 355 & 31 & 25 & 15 \\
\hline$p B C-p P N$ Library & 1002 & 208 & 24 & 119 & 119 \\
\hline$p B N-p$ PC Library & 1448 & 458 & 54 & 52 & 106 \\
\hline$p B N-p P N$ Library & 934 & 122 & $\mathbf{2 2 8}$ & $\mathbf{2 1 1}$ & $\mathbf{1 8 2}$ \\
\hline Total & $\mathbf{4 4 7 7}$ & $\mathbf{1 1 4 3}$ & & & 17 \\
\hline
\end{tabular}

Lastly, after the consolidation of the duplicated results, a final high-quality dataset of 182 PPIs was obtained (Supplementary Table S6). More than half of these interactions (106) were found with the NC bait-prey pair. The second pair retrieving more filter-passing interactions was the NN pair, which suggested a higher degree of detection of putative interactions for the $\mathrm{N}$ bait fusion. A total of 13 interactions were detected in two different bait-prey pairs, and, interestingly, seven of them involved the Bam 35 membrane structural component P25 (Supplementary Table S6).

\subsection{Challenging Y2H Single Hits from the Fragment Genomic Library Using ORF Pairwise Y2H Assays}

To further validate the detected interactions from the $\mathrm{Y} 2 \mathrm{H}-\mathrm{HTS}$ screening, which were obtained using computational analysis of the original Illumina dataset, 33 randomly chosen interactions were re-evaluated (Table 3). In this case, binary $\mathrm{Y} 2 \mathrm{H}$ was used to individually test the interactions between the complete host proteins and their putative viral partners. Prey vectors containing the selected HER1410 ORFs were obtained and assayed with the correspondent bait vectors, resulting in seven confirmed interactions (Supplementary Figure S5). On the other hand, twelve interaction pairs could not be confirmed since even though the yeast expressing both Bam 35 and B. thuringiensis proteins was able to grow, the maximum 3AT tolerated was equal to or smaller than that of the yeast expressing only the 
prey or bait protein (Table 3). Strikingly, only NC interactions could be confirmed using this method, coinciding with the bait-prey combination that is more commonly found within the HTS-predicted interactions. Most of the confirmed interactions were detected at high 3AT concentrations, which indicated a strong interaction.

Table 3. Binary $\mathrm{Y} 2 \mathrm{H}$ screening of 33 selected putative interactions between Bam35 (B35) baits and B. thuringiensis (Bt) preys using full-length proteins. The maximum 3AT concentration at which yeast growth was detected is gradually colored from red (low concentration) to green (high concentration). "No growth" indicates that no yeast growth was observed at any 3AT concentration.

\begin{tabular}{|c|c|c|c|c|c|c|}
\hline $\begin{array}{c}\text { Bait } \\
\text { (B35ORF) }\end{array}$ & $\begin{array}{c}\text { Prey } \\
\text { (BtORF) }\end{array}$ & $\begin{array}{l}\text { Max. 3AT (mM) } \\
\text { (B35ORF_Emptyprey) }\end{array}$ & $\begin{array}{c}\text { Max. 3AT (mM) } \\
\text { (Emptybait_BtORF) }\end{array}$ & $\begin{array}{l}\text { Max. 3AT (mM) } \\
\text { (B35ORF_BtORF) }\end{array}$ & Interaction & $\begin{array}{l}\text { Bt Protein } \\
\text { Coverage }\end{array}$ \\
\hline pBC_06 & pPC_pepA(24805) & 0.1 & 50 & 0.1 & $\mathrm{~N} / \mathrm{A}$ & 0.33 \\
\hline pBC_10 & pPC_dapF(25140) & 50 & 10 & 10 & $\mathrm{~N} / \mathrm{A}$ & 0.44 \\
\hline pBC_25 & pPC_hutI(18010) & 0.025 & 50 & No growth & No & 0.43 \\
\hline $\mathrm{pBC} \_25$ & pPC_pepA(24805) & 0.025 & 50 & 0 & $\mathrm{~N} / \mathrm{A}$ & 0.33 \\
\hline pBC_26 & pPN_pepD(12045) & No growth & 25 & No growth & No & 0.37 \\
\hline pBC_31 & pPC_hutI(18010) & 0 & 50 & 0 & $\mathrm{~N} / \mathrm{A}$ & 0.43 \\
\hline pBC_31 & pPC_pepA(24805) & 0 & 50 & 0 & $\mathrm{~N} / \mathrm{A}$ & 0.33 \\
\hline pBC_31 & pPC_tyrS(25855) & 0 & 10 & 0 & $\mathrm{~N} / \mathrm{A}$ & 0.15 \\
\hline pBN_03 & pPC_pbpX(02235) & No growth & 0.1 & No growth & No & 0.44 \\
\hline pBN_06 & pPC_pepA(24805) & No growth & 0.1 & No growth & No & 0.33 \\
\hline pBN_08 & pPN_lexA(18215) & No growth & 0.1 & No growth & No & 0.42 \\
\hline pBN_11 & pPC_pbpX(02235) & No growth & 0.1 & No growth & No & 0.44 \\
\hline pBN_15 & pPC_iap(27190) & No growth & 0.1 & 25 & Yes & 0.76 \\
\hline pBN_15 & pPN_(30985) & No growth & 0.1 & No growth & No & 0.18 \\
\hline pBN_16 & pPC_iap(27190) & No growth & 0.1 & 25 & Yes & 0.76 \\
\hline pBN_16 & pPN_(30985) & No growth & 0.1 & No growth & No & 0.18 \\
\hline pBN_19 & pPC_iap(27190) & No growth & 0.1 & 50 & Yes & 0.76 \\
\hline pBN_19t & pPC_ompR(22050) & 50 & 10 & 100 & Yes & 0.99 \\
\hline pBN_19t & pPN_menF(24455) & 50 & 0.1 & 50 & $\mathrm{~N} / \mathrm{A}$ & 0.31 \\
\hline pBN_20 & pPC_purL(01870) & No growth & 0.1 & No growth & No & 0.24 \\
\hline pBN_22 & pPC_yadS(28175) & 0 & 0.1 & 50 & Yes & 0.74 \\
\hline pBN_22 & pPN_(30985) & No growth & 0.1 & 0 & $\mathrm{~N} / \mathrm{A}$ & 0.18 \\
\hline pBN_24 & pPN_usp(26960) & 0.025 & 0.1 & 0.1 & $\mathrm{~N} / \mathrm{A}$ & 0.54 \\
\hline pBN_25 & pPC_hutI(18010) & No growth & 0.1 & No growth & No & 0.43 \\
\hline pBN_25 & pPC_pepA(24805) & No growth & 0.1 & No growth & No & 0.33 \\
\hline pBN_25t & pPC_pepA(24805) & 25 & 0.1 & 25 & $\mathrm{~N} / \mathrm{A}$ & 0.33 \\
\hline pBN_25t & pPN_pepA(24805) & 25 & 0.1 & 25 & $\mathrm{~N} / \mathrm{A}$ & 0.33 \\
\hline pBN_26 & pPC_(16200) & No growth & 0.1 & 3 & Yes & 0.89 \\
\hline pBN_26 & pPN_(30985) & No growth & 0.1 & No growth & No & 0.18 \\
\hline pBN_27 & pPC_iap(27190) & 0.025 & 0.1 & 50 & Yes & 0.76 \\
\hline pBN_27 & pPN_(30985) & No growth & 0.1 & No growth & No & 0.18 \\
\hline pBN_27t & pPN_usp(26960) & 3 & 0.1 & 0.1 & $\mathrm{~N} / \mathrm{A}$ & 0.54 \\
\hline pBN_31 & pPC_hutI(18010) & 0.1 & 0.1 & No growth & No & 0.43 \\
\hline
\end{tabular}

In this case, rather than the enrichment category, the percentage of the protein sequence covered by the original library fragment was found to be a relevant indicator for the fulllength-fragment correlation confirmation rate. Thus, all the interactions showing a host protein coverage above $74 \%$ were validated, while the rest (coverage under $54 \%$ ) could not be validated for the full-length protein (Table 3). On the other hand, although only $21 \%$ of the retested interactions could be confirmed with this method, we cannot rule out that true interactions between viral proteins and host protein fragments or domains, which could have been hidden within the full-length construct, occurred. In conclusion, the confirmed positives rate provided a high confidence level for the interactions detected in our screening, at least for those involving high coverage fragments. These results suggested that the protein coverage of these fragments could also be useful as an additional confidence score in the Y2H-HTS approach to link protein fragment interactions with full-length PPIs. 
2.3. Bam35-B. thuringiensis Y2H-HTS Predicted the Interactome: Clear the Forest to Predict PPIs

From the final dataset including the 182 selected interactions, 54\% included viral proteins that were functionally linked to the "Virion structure and DNA packaging" functional group (Figure 4). Among them, both P26 and its non-transmembrane domain variant (P26t) retrieved the highest number of interactions (17 and 15 respectively), followed by P25 with 11 interactions (Table 4).

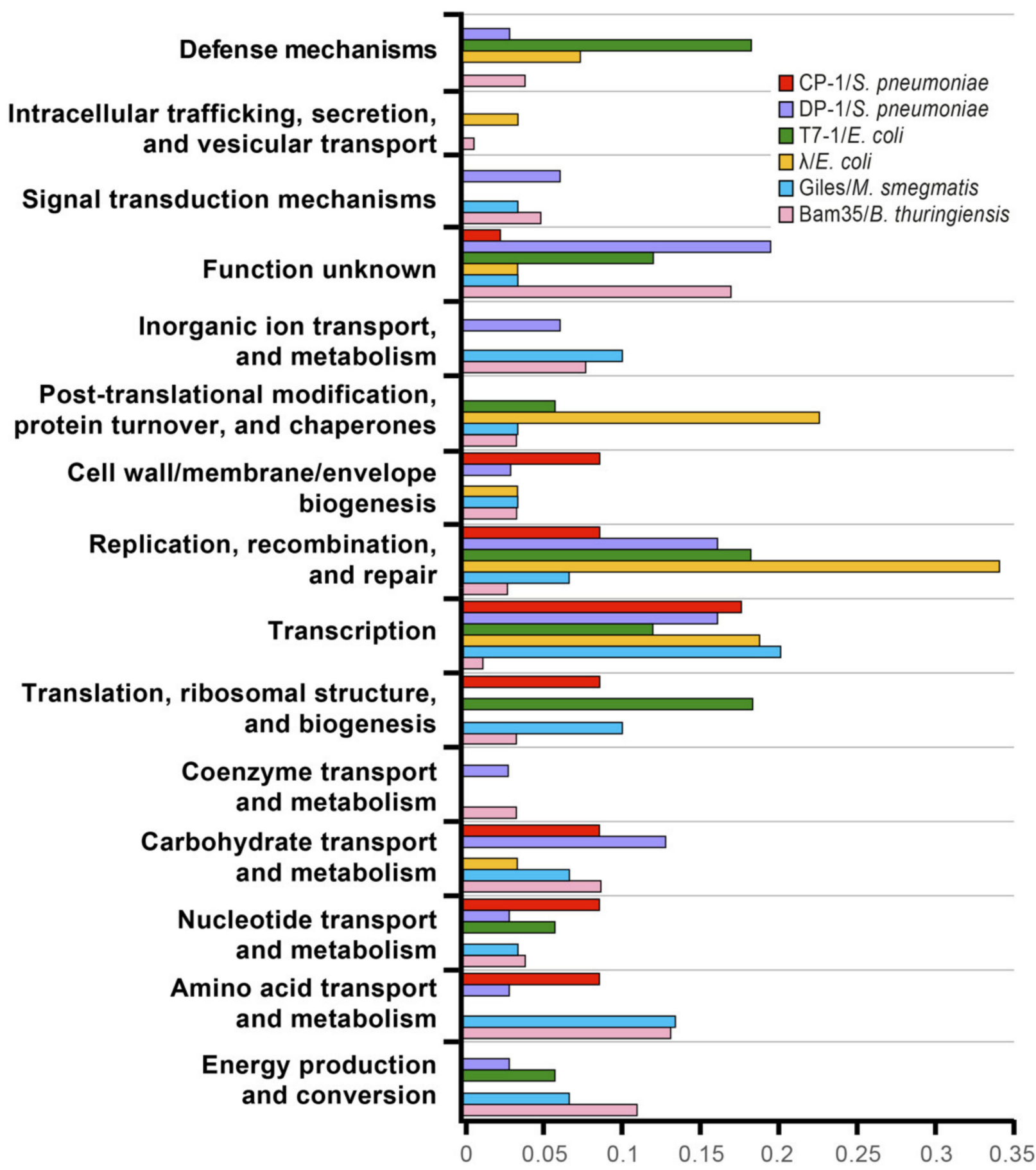

Figure 4. Interactions between functional groups of proteins. Stacked bar chart representing the proportion of interactions between the functional groups of Bam 35 and the COG groups of B. thuringiensis. The X-axis represents the percentage of interactions that involved a defined COG group out of the total interactions that involved a defined Bam 35 functional group. The number of total interactions is indicated for each combination inside the bars. 


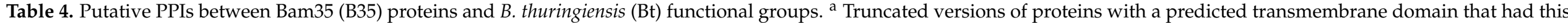
domain removed are labeled with a " $t$."

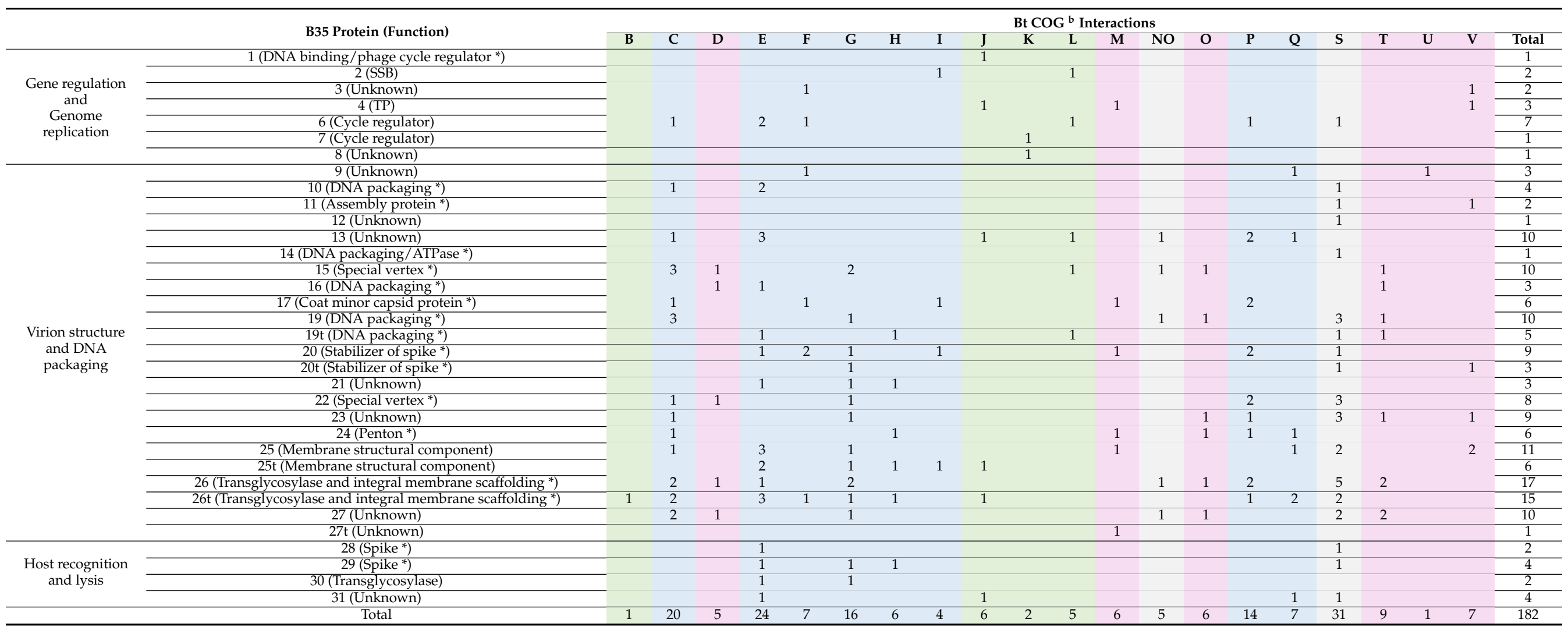

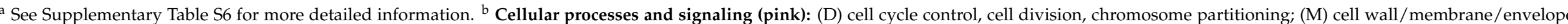

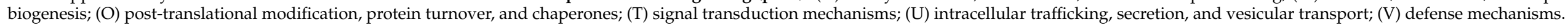

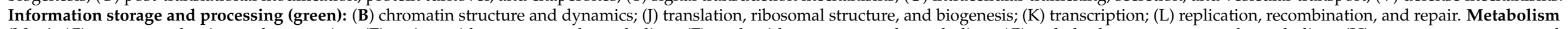

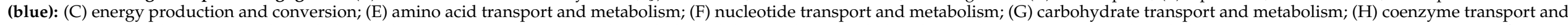

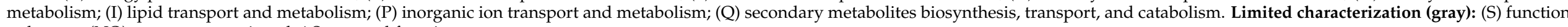
unknown, (NO) no category assigned. * Suggested function. 
In general, host metabolic proteins seemed to interact to a higher extent with viral proteins than the rest of the clusters of orthologous groups (COGs), with more than half of the total PPIs including this type of proteins (Figure 4). Interestingly, viral proteins involved in "gene regulation and genome replication" targeted "information storage and processing" host proteins in a higher proportion compared to other viral groups, indicating a possible link between these two functional groups. As shown in Supplementary Figure S6, these host partners did not connect different viral functional groups but remained restricted to the replication and regulation of viral nodes. The different viral functional groups of proteins seemed to be connected mostly by metabolism host proteins. However, no connection was observed between "host recognition and cell lysis" and "gene regulation and genome replication" groups, and only one node linked the three groups of viral proteins. This interactor could indeed be a hub due to its role as an aminopeptidase, which is a cytosolic protein that is presumably involved in the processing and regular turnover of intracellular proteins [49].

Analysis of the Bam35-B.thuringiensis interactome also allowed for the identification of specific patterns and remarkable interactions (Figure 5 and Supplementary Table S6). Importantly, the only previously characterized Bam35-B. thuringiensis PPI, which consisted of the interaction between the viral P7 and the host LexA protein [28], was detected in our final dataset. Interestingly, according to our results, this host protein could also interact with the viral protein P8, which is a protein of unknown function that, similar to P7, belongs to the "gene regulation and genome replication" functional group. Moreover, as explained above, the non-transmembrane variant of the protein P26 (P26t) appeared to be a hub in the interactome since several host interactors were identified that also interacted with other viral proteins. Furthermore, the viral membrane protein P25 appeared to be a structural hub that partnered with several transport proteins. On the other hand, in agreement with the intraviral interactome results [19], the complete protein P26 interacted with host proteins that were also linked to several structural proteins, especially those that are involved in the special vertex formation (P15, P16, P19, P22), as well as P23 and P27, which are structural proteins of unknown function. Therefore, these proteins appeared to form a cluster that was connected by a high number of host proteins, many of them linked to membrane-related transporters (Supplementary Table S6). Importantly, this "special vertex cluster" contained several high-confidence interactions, including validated interactions, category A interactions, and fragments that significantly covered the complete host proteins.

Contrary to structural viral proteins that are highly interconnected with host proteins, those involved in "gene regulation and genome replication" interacted independently. This was the case, for example, for the B35SSB (P2) [50], which remained outside of the network, interacting only with an acetate CoA transferase and a primosomal protein. In general, the obtained network showed a highly interconnected system, where some viral proteins could act as hubs in the bacteria-virus interactome [19]. Lastly, no interactions above the thresholds were detected between the host proteins and the viral P5 (DNA polymerase); P18 (major capsid protein), which was somewhat expected by their function; and P32. P32 overlapped with half of the P30 sequence (see Supplementary Figure S1) and, accordingly, both proteins shared most of the interactions in the intraviral interactome [19]. However, in this work, the two interactions of P30 were not detected with P32, even in the raw data, indicating that those interactions were mediated by the N-terminal half of P30. 

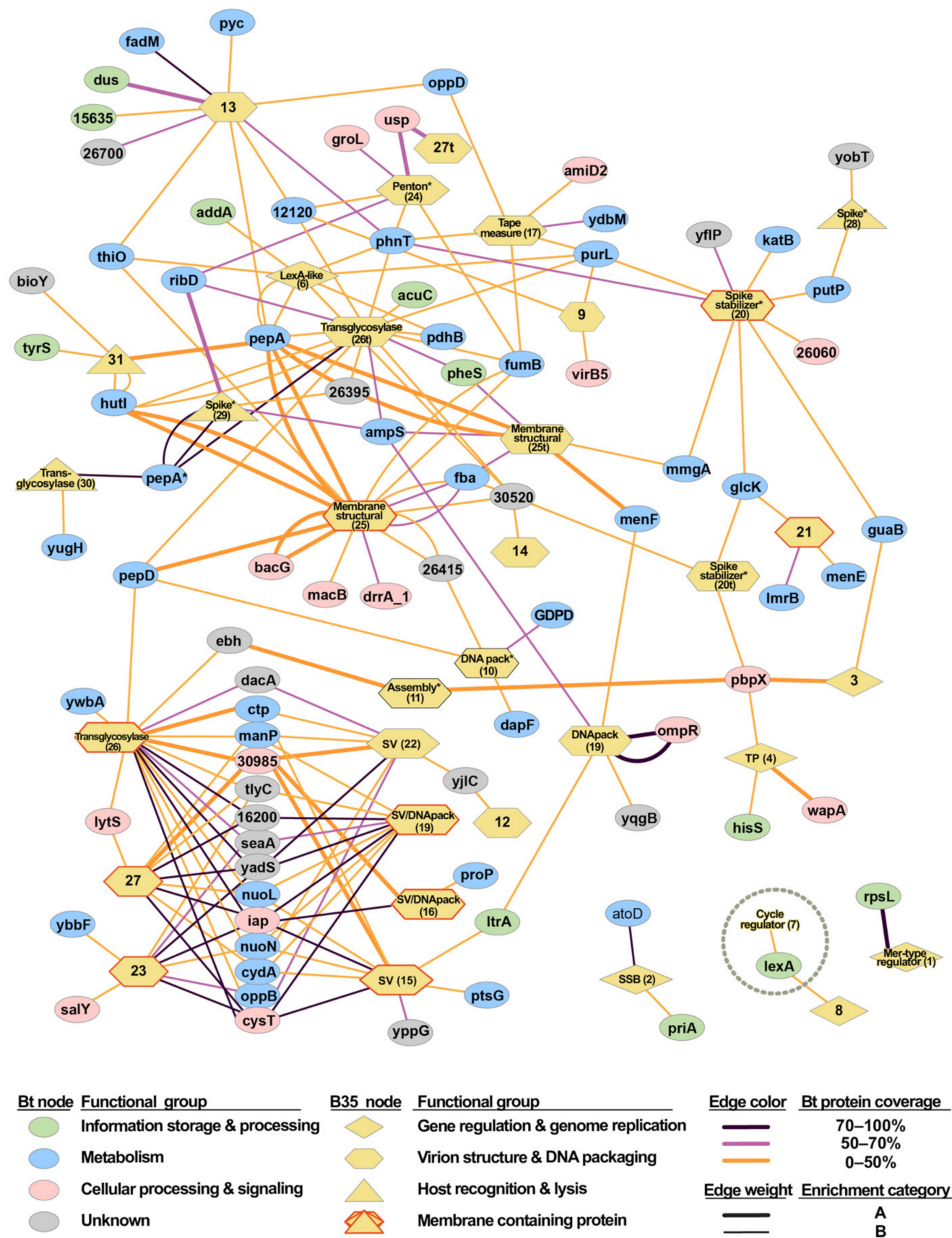

Edge weight Enrichment category

Membrane containing protein

Figure 5. Bam35-B. thuringiensis protein interaction network based on the Y2H-Illumina screening. Network of the 182 detected interactions (195 bait-prey pair combinations) between the host proteins and the viral proteins (Supplementary Table S6). Host proteins (Bt nodes) are represented by ellipses colored according to their functional groups and the viral proteins are represented by yellow nodes shaped according to their functional groups. Viral nodes are labeled by their known or suggested $\left({ }^{*}\right)$ function and their gene number (between brackets) is indicated in Supplementary Figure S1. SV stands for special vertex localization. Host proteins are identified by their annotated function or, for the unknown function proteins, their locus number in the HER1410 genome (accession numbers available in Supplementary Table S6). Each interaction (bait-prey combination) is represented as a line connecting two nodes. Line colors indicate the coverage of the host protein by the detected prey fragment, where the line weight indicates the enrichment category of the interaction (B for prey proteins detected as $0.25-10 \%$ of the sample counts and A for 10-100\%). The interaction between the viral P7 and the host LexA that was detected in this work and previously published in Caveney et al. [28] is indicated with a gray circle. PepA* refers to the M42 family metallopeptidase that is encoded by the host gene HBA75_23575 and PepA refers to the cytosol aminopeptidase that is encoded by the host gene HBA75_24805. 


\section{Discussion}

\subsection{A Proficient Y2H-HTS Method to Detect Multiple Phage-Host PPIs}

To date, few attempts have been made to obtain bacteria-phage interactomes. Among them, the most complete includes an ORF collection of 3974 (94\%) of the known E. coli K-12 CDS and 68 out of 73 CDS of phage lambda, whose interactions were tested using a pool-arrayed screening approach [36,51]. This method was also used in the case of Streptococcus pneumoniae and its phages, although with a less representative host ORFeome [38]. Others turned to fragment-based approaches for PPI analysis, like those of Pseudomonas phage $\phi \mathrm{KMV}$ and that of mycobacteriophage Giles [35,39]. However, those approaches require ORFeome libraries and/or individual clone identification, which negatively impacts the efficiency and the potential generalization of the method to less characterized models. These limitations prompted us to use a combination of a random fragment library, and a novel pipeline, which allowed us to benefit from high-throughput sequencing to study the interactome of Bam 35 and its host, namely, B. thuringiensis, and which could readily be implemented toward other systems. Coupling $\mathrm{Y} 2 \mathrm{H}$ and HTS can generally be performed using two strategies. An all-versus-all strategy using library recombination approaches or the use of barcode indexing, which enables simultaneous sequencing of interacting preys from multiple separate assays in a single Illumina paired-end run $[44,45,47,52]$. In our case, the latter proved more appropriate since Bam 35 has a limited number of viral genes that were already available and tested for autoactivation in $\mathrm{Y} 2 \mathrm{H}$ [19]. We also generated and thoroughly analyzed the random fragments genomic library of $B$. thuringiensis HER1410, which is a strain that is highly sensitive to Bacillus phage infections [17,53]. Based on this, our custom HER1410 library and the 32 annotated CDS from phage Bam35 were screened using $\mathrm{Y} 2 \mathrm{H}$. This resulted in a large and high-throughput screening comprising 156 assays (see Figure 3), which potentially tested more than 80,000 protein-protein pairs. A total of 4477 interactions were initially detected, which were filtered and ranked to establish a threshold that differentiated low confidence interactions (or the background) from reliable interactions. In our work, we showed that the Y2H-HTS approach was highly selective for in-frame fragments, whose presence in the original library was at $1-2 \%$, in line with previous work [54]. Indeed, some prey fragments from the $\mathrm{Y} 2 \mathrm{H}$ positive results were not found in the libraries' sequencing data. This suggested that these prey were scarce within the libraries and could not be detected, despite the high sequencing depth of the library (over $200 \times$ ). Altogether, our results indicated that a higher depth could reveal the presence of additional fragments, increasing the calculated quality of the library.

The establishment of categories based on the enrichment of the prey fragments per sample was shown to keep one-fourth of the interactions while retaining $98 \%$ of the Illumina reads (Table 1). Moreover, as previously proposed [46,47,55], the enrichment of the interactions, i.e., the normalized number of sequencing reads, could reflect higher affinity between the pray and bait, as more stable interactions would be more common among the pooled positive colonies. In line with this, the validation of these categories by single-colony sequencing confirmed the strong correlation between the number of positive colonies and their enrichment in the Illumina data. We could therefore conclude that the analysis of the results provided a quantitative value to the dataset, with reduced bias and high sensitivity.

It is widely recognized that one of the main limitations of $\mathrm{Y} 2 \mathrm{H}$ is the high rates of false positives and false negatives. Caufield et al. [56] showed that the false-negative rate can be considerably reduced through the use of different vector pairs. Particularly, permutations of $\mathrm{C}$ - and $\mathrm{N}$-terminal $\mathrm{Y} 2 \mathrm{H}$ vectors increase the coverage of interactome studies, reduce the number of false negatives, and detect strong interactions [57]. However, for bacterial and phage-bacteria interactomes that include ORF or genomic libraries, these libraries are usually cloned in the $\mathrm{N}$-fused variant for both the prey and bait, possibly due to the restrictions imposed by the difficulty of creating "in-frame" C-terminal fusions [35,38,39,58,59]. In this work, the C-terminal fusion library gave rise to a high number of putative interactions when combined with the $\mathrm{N}$-fusion viral proteins, despite harboring fewer in-frame 
fragments. A total of 13 out of 182 putative interactions were found in more than one combination, showing a lower overlap than for intraviral interactomes [19].

We also used several methods that aimed to maximally reduce false-positive interactions, such as the competitive inhibitor $3 \mathrm{AT}$, which prevents bait self-activation, the addition of negative controls including the empty plasmids, and the identification and removal of "sticky" prey. Remarkably, a large percentage (97\%) of the prey proteins that were found in the empty combinations were also tagged as "sticky." Importantly, the highthroughput technique that was used in this work allowed for the identification of all prey partners, enabling the effective discrimination of specific interactors from "sticky" proteins and other false positives, as suggested elsewhere [47,60]. After the efficient removal of a high number of false positives ( $85 \%$ ) by these filters, 182 candidate interactions could be identified.

Validation of high-throughput study results is hardly feasible, though confidence scores have proven useful $[47,61,62]$. In addition, $\mathrm{Y} 2 \mathrm{H}$ approaches can validate their methods by retesting the interactions with pairwise $\mathrm{Y} 2 \mathrm{H}$ involving the constructs that were detected in the first screen [36,47]. In our case, we implemented an alternative validation approach in which we investigated the correlation between interactions involving complete proteins and their domains, essentially challenging the screen. Interestingly, only interactions whose initial prey fragment highly covered the complete protein $(>74 \%)$ were positive in the new assay. However, it should be noted that the unconfirmed interactions from this method should not be excluded from biologically relevant interactions. Indeed, although some interactions that require full-length proteins could be missed [52], the use of protein fragments can increase the sensitivity of the screening, as shown in Yang et al. [45], where some known interactions were only detected when domains or domains vs. full-length proteins were assayed. Likewise, the previously described interaction between LexA and P7 [28] was detected in our screen with a fragment covering $42 \%$ of the protein. Therefore, notwithstanding the limitations of the fragment-based $\mathrm{Y} 2 \mathrm{H}$, our results indicate that the use of a random fragment library not only expanded the interaction space but could also be useful for domain interaction determination and additionally provided a protein length coverage cutoff criteria.

\subsection{The Bam35-Bt Y2H Interactome Revealed the Clustering of Special Vertex Proteins and a Wide Modulation of Host Cell Metabolism}

As plasmidial prophages, betatectiviruses have a particular lysogenic cycle that raises many questions about their evolution and maintenance [63,64]. Disclosing the virushost interactions at the molecular level would shed some light on this growing group of enigmatic viruses and their evolutionary synergy with relevant human and animal pathogens. Based upon enrichment, specificity, and biological meaning, we could obtain a virus-host interactome that certainly allowed us to identify some common patterns and prey partners of interest.

In previous works, structural proteins were usually not involved in host-virus interactions as they are mainly involved in most intraviral interactions [36]. Conversely, a high proportion of the detected Bam35-B. thuringiensis PPIs are involved in "virion structure and DNA packaging." When compared with previous works on phage-host interactomes, functional annotation frequencies of the interacting host partners do not share similar patterns (Figure 6). Strikingly, although a higher frequency in protein processing and gene regulation was associated with phage lambda's lysogenic state, these categories were not specifically represented for Bam 35 and Giles phages, which are also temperate. Nevertheless, we did detect protease enrichment (see below), which is known to be important for phage lambda, among the Bam35-host interactions. Previous phage-host research mainly identified host proteins that are involved in transcription, replication, recombination, and repair functions. However, the Bam35 proteins involved in DNA replication showed very few interactions. Furthermore, in agreement with an episomal lysogenic stage in which the viral genome could be replicated only by viral factors, host proteins involved in DNA replication and recombination were uncommon targets. In turn, 
phage proteins largely targeted host metabolic processes and transport proteins, which would be modulated or hijacked during viral lysogeny and/or lytic cycle development. Among them, host partners involved in menaquinone metabolism (MenF, MenE) should be highlighted here. Menaquinone (Vitamin K12) is involved in anaerobic metabolism and is essential for complex colony formation [65], which is a process that is strongly influenced by betatectivirus [29]. Similarly, two viral proteins, namely, the spike stabilizer P20 and the protein of unknown function P21, interact with the host glucokinase (GlcK), which might be related to a previously reported faster glycogen metabolism in the GIL01 and GIL16 lysogenic strains [29].

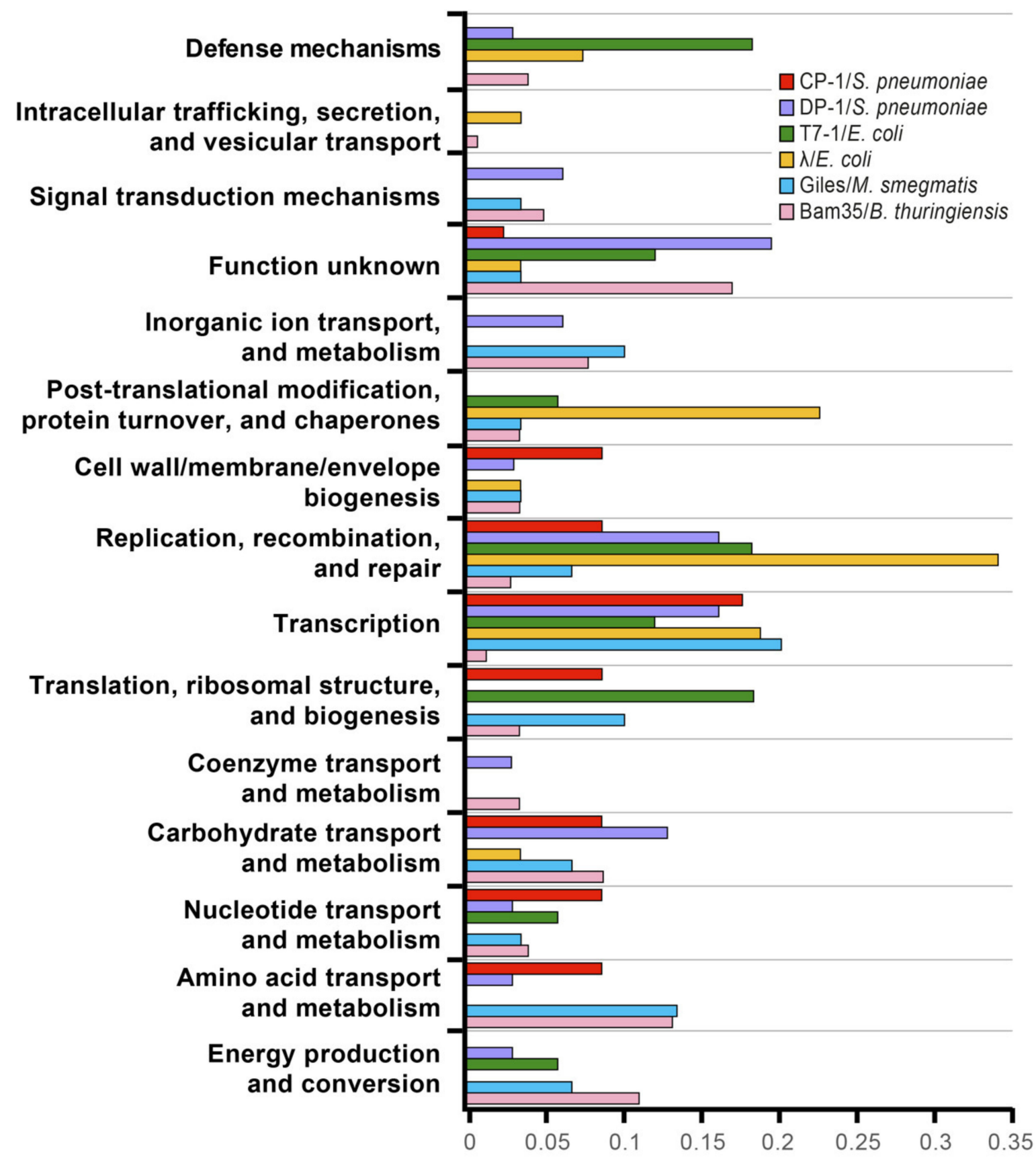

Figure 6. Frequency of phage-targeted proteins and their functional classes adapted from Mariano et al. [38]. The interactions between Giles and Mycobacterium smegmatis (blue) [39] and the interactions detected in this work between Bam35 and B. thuringiensis (pink) were added. 
Interestingly, despite the high differences in both the virus and the host, the Gileshost interactome approach is the most similar to ours since it is based on a host genome fragments library; Giles is also a temperate phage, and the results also pointed to a high viral influence in the host metabolism [39]. Furthermore, in line with our results but using a different approach, a high-throughput proteomic analysis of the effect of the betatectivirus-related plasmid pBClin 15 on its host revealed a significant impact of pBClin15 on different pathways of central metabolism during growth [66]. Similarly, diverse RNAseq analyses highlighted the influence of phages in membrane proteins, transporters, and metabolism [67-70]. On the other hand, some host interactors that were detected in our study were similar to those found in other phage-host interactomes, including $\mathrm{ABC}$ transporters, NADH-quinone oxidoreductases, primosomal proteins, and phosphate regulatory proteins $[36,38,39]$.

Among the 182 different interactions, $12.6 \%$ involved different types of peptidases. PepA (locus HBA_24805) is linked to the three functional groups of viral proteins (Supplementary Figure S6). This protein presumably functions in the processing and regular turnover of intracellular proteins, which might be subverted during the viral infection. This could also be the case for a putative M42 metalloprotease (locus HBA75_23575, also annotated as PepA) and the aminopeptidase AmpS, which interact with Bam35 proteins from the structural module, including the lytic proteins P26 and P30. Accordingly, E. coli gene expression analysis during bacteriophage PRD1 infection showed that many proteases were highly induced during virion assembly [67]. Interestingly, the orthologs of these three peptidases in Bacillus subtilis interact with each other (String database) [71]. In line with this, proteases are involved in lambda-E. coli interactions and linked to the viral cycle regulation, although these interactions could not be detected using $\mathrm{Y} 2 \mathrm{H}$, probably due to their weak and transient nature [36,40]. Another protease that was found in the interactome, namely, PepD, was reported to negatively affect biofilm formation [72]. Therefore, the detection of PepD as a host target, as well as a spore coat protein, could also be linked to the influence of Bam35/GIL01 lysogeny on the B. thuringiensis sporulation rate and biofilm formation [29].

The Bam35 inner membrane is generated by recruitment of the host lipid membrane and results in a modification of membrane thickness and curvature. This process was proposed to be carried out by a cluster of viral proteins that includes the phage tape measure (P17) and major capsid proteins (P18) [12]. Interestingly, P17 interacted with P18 but also with transmembrane-containing proteins $\mathrm{P} 25$ and P26, which, in turn, interacted with several host proteins, including transporters that were associated with the host membrane (Figure 5). P25 is the second most abundant protein in purified Bam $35 \mathrm{c}$ particles [11] and thus could play a key role in the host membrane modifications. The P26 variant without the transmembrane domain also lacks a C-terminal region of unknown function, which may explain the different sets of interaction between P26 and P26t (Figure 5), as previously reported [19]. Moreover, the lack of P26t in the special vertex cluster suggested a role of the removed 177-250 residues in these interactions. On the other hand, the P26t variant shared prey partners with P17, P24, and P29, which are also direct interactors. These results are in line with the putative role of P26 as a scaffold protein for other structural elements from the inner membrane and the viral capsid [19], as well as with its proposed function as a hub for the viral-host interaction.

Several viral proteins were clustered in the Bam35-host interactome by their common interactions with numerous bacterial nodes (Supplementary Figure S7). The suggested function for four of them (P15, P16, P19, and P22) was associated with the special vertex $[11,19]$. The clustering of these proteins in a similar host-phage interaction environment supported their proposed function. On the other hand, the localization of PRD1 P15, which is the Bam35 lytic enzyme P26 counterpart, in the special vertex is controversial [73,74]. Interestingly, in Bam35, our phage-host interactome suggested that P26, along with the proteins of unknown function P23 and P27, would be part of the special vertex cluster (Supplementary Figure S7). P23 has a transmembrane domain and almost all of its interaction partners include different transporter proteins, hinting toward a role as a membrane- 
associated protein that is related to the special vertex. P27 is also a transmembrane protein and was suggested as the penton protein [12], although the intraviral interactome results downplayed this possibility [19]. The non-transmembrane variant of P27 only interacts with a host N-acetylmuramoyl-L-alanine amidase, which is a protein that degrades the cell wall peptidoglycan. This host protein also interacts with P24, which is proposed to be the penton protein and is related to the transglycosylase (P30), presumably making it responsible for the viral entry mechanism that is associated with the spikes [19,21]. Thus, P27 may be an anchoring virion protein whose function is related to both viral entry and release. These results could also suggest the recruitment in the virion of an additional host amidase that would help in the viral entry. Another interesting putative partner of P24 is a GroEL chaperonin, which is thought to assist the insertion of PRD1 proteins in the virion membrane and is essential for PRD1 assembly [75]. E. coli-PRD1 RNAseq data showed high expression levels of the host GroEL during assembly, while in the case of pBClin15b, which displays cryptic prophage behavior, GroEL was downregulated [66,67]. Thus, it is tempting to speculate that this chaperone may also have a role in the assembly of Bam35.

Importantly, all the proteins that are clustered in the "special vertex group" have a predicted transmembrane domain [11], whereas the variants lacking this domain did not appear in this group. This could explain their interaction with the same partners, which are mostly membrane-related transporters and may help the phage to attach to the host membrane. Particularly, the strong interactions with a putative phage tail tape measure protein from the putative prophage pLUSID3 (30985 in Supplementary Figure S7) could be have been due to the protein region covered by the $\mathrm{Y} 2 \mathrm{H}$ fragment, which comprises a predicted transmembrane domain. This domain appears specific to Bacillus phages and therefore would suggest interactions between elements of the mobilome. However, this protein is puzzling as Caudovirales lack any membrane within their viral particle. Furthermore, six out of the seven confirmed interactions belonged to this cluster (Supplementary Figure S7). Remarkably, within these, the enterotoxin/SH3 domain protein (Iap in Supplementary Figure S7) was also annotated as the conserved virulent factor EntA [53,76]. SH3 domains are known to be involved in protein-protein interactions and cell wall recognition and binding [77]. Since the transglycosylase P26 does not possess any signal peptide [21], it is also possible that the enterotoxin can be recruited by the phage to reach the membrane and the cell wall during and while contributing to lysis.

One of the most relevant interactions that was detected with Y2H-HTS in the Bam35HER1410 model was the previously described direct interaction between the viral P7 and the host LexA, which is key for maintaining lysogeny [18,27]. Here, the LexA fragment comprised the second half of the protein (residues 121 to 206), suggesting that the interaction domain was located in this region, and it was sufficient to establish the interaction. Importantly, the detection of this previously known (and unique) interaction between Bam35 and $B$. thuringiensis provided confidence in our method. Only one other viral protein interacts with the host LexA, namely, P8. Interestingly, the ORF8 is located in a highly variable region of tectiviruses whose ORFans may alter phage regulatory functions, influencing phage and possibly also host fitness [78]. However, the lack of sequence similarity does not provide any hints about its specific function. Since the only detected host partner of P8 is LexA, it is tempting to suggest a role of P8 in viral cycle control. Particularly, as the ORF8 is located at the end of a gene cassette that is responsible for maintaining the lysogenic cycle $[18,27]$, the P8-LexA interaction might also contribute to the fitness and regulation of the lysis-lysogeny switch. P8 interacts with the viral LexA-like activator protein (P6) and it shares with the latter and P7 the interactions with structural proteins P24 and P26. This suggests that all the regulatory proteins could be present in the viral particle, allowing their involvement in the very early infection events, as proposed previously [19]. Moreover, P6 interacts with PepA (locus HBA_24805), whose E. coli ortholog is involved in transcription and recombination [79], and therefore it could also be related to the Bam35 life cycle regulation. 
Another key interaction that we expected to uncover in this work was the identification of a viral protein receptor. Several host proteins in our interactome may be candidates to be the Bam 35 receptor, including membrane-associated proteins, such as metabolite transporters. As such, it is tempting to speculate that the host protein PutP $\mathrm{Na}^{+} /$proline symporter could be the receptor, as it showed interactions with the spike protein P28 and the putative spike stabilizer (P20). However, PutP belongs to an osmotically inducible operon [80], which downplays its role as the viral receptor under normal growth conditions. Therefore, it is likely that the viral receptor is not present in our libraries. Alternatively, this and other interactions may be missed by the establishment of a threshold, as shown in Yang et al. [45], and false positives can arise for the same reason. The knowledge of literature-based interactions was proven to be key in this matter [47]. Since our approach is the first one in the tectiviruses-host interactions field, we combined the use of several quality filters with the previous biological knowledge of the Bam35-Bacillus model and previous virus-host studies. Therefore, the high-throughput Y2H screening of Bam35- $B$. thuringiensis, including a high number of host proteins and tested interactions, resulted in the detection of multiple potentially interesting and novel PPIs. Although Bam35-B. thuringiensis interactions need to be further analyzed with other PPIs analysis techniques and their biological relevance remains to be explored further, they open the door to new types of host-phage interactions and a deeper understanding of Bam35 and tectiviruses.

\section{Materials and Methods}

\subsection{Nucleotides and DNAs}

DNA oligonucleotides were purchased from IDT (Coralville, IA, USA).

Entry donor vectors $\mathrm{pDONR} / \mathrm{Zeo}$ and $\mathrm{pCR}^{\mathrm{TM}} 8 / \mathrm{GW} / \mathrm{TOPO}^{\mathrm{TM}}$ were purchased from Invitrogen. The yeast two-hybrid system (Y2H) expression vectors pGADCg, pGADT7g, pGBKCg, and pGBGT7g [57] were available in-house.

\subsection{Bacterial and Yeast Strains}

The Bacillus thuringiensis HER1410 strain was originally obtained from the culture collection of the Félix d'Herelle Reference Center for Bacterial Viruses of the Université of Laval (https: / / www.phage.ulaval.ca) and can be retrieved with host HER number 1410 (last accessed 12 October 2021).

E. coli TOP10 was used for genomic HER1410 libraries generation. The S. cerevisiae prey strain Y187 (MAT $\alpha$, ura3-52, his3-200, ade2-101, trp1-901, leu2-3, 112, gal4 $\Delta$, met, gal80 $\Delta$,

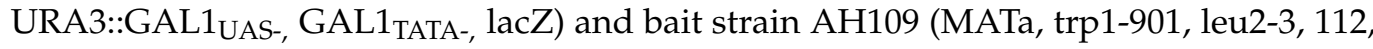

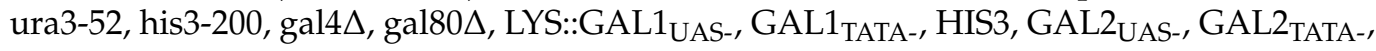
ADE2, URA3::MEL1 $1_{\text {UAS-, }}$ MEL1 $1_{\text {TATA- }}$, lacZ) were used for the $Y 2 H$ screen [81].

\subsection{Genomic Library Construction}

To generate a genomic library of B. thuringiensis HER1410, a four-step procedure was followed, as illustrated in Figure 1.

\subsubsection{Generation of the Genomic Library and Cloning into the Donor Vector}

The genomic DNA (gDNA) of $B$. thuringiensis HER1410 was isolated using the DNeasy Blood and Tissue kit (Qiagen) and concentrated via ethanol precipitation [82]. The extracted gDNA was partially digested with the restriction enzyme CviAII (New England Biolabs) and subsequently 5'-dephosphorylated with Calf Intestinal Alkaline Phosphatase (New England Biolabs). CviAII cuts on a sequence motif "CATG," which is highly frequent on bacterial genomes, with 17,370 sites in HER1410 genome, cutting on average every 356.8 base pairs (bp). The digested DNA was separated by agarose electrophoresis and an agarose block with DNA fragments spanning between about 450-750 base pairs (marker bands) was cut out, subjected to gel-extraction DNA purification with QIAquick Gel Extraction Kit (Qiagen), and purified using ethanol precipitation [82]. The DNA fragments size was chosen to meet Illumina technical requirements and according to the gene size 
distribution. In HER1410, 75\% of the protein-coding genes are shorter than $1 \mathrm{~kb}$, longer fragments might have led to an ample generation of chimeric genes. Gap filling of the $3^{\prime}$ overhangs and A-tailing were performed using Taq DNA polymerase. The library was subsequently cloned into the plasmid $\mathrm{pCR}^{\mathrm{TM}} 8 / \mathrm{GW} / \mathrm{TOPO}^{\circledR}$ using the $\mathrm{pCR}^{\mathrm{TM}} 8 / \mathrm{GW} / \mathrm{TOPO}^{\mathrm{TM}}$ TA Cloning Kit (ThermoFisher).

\subsubsection{Amplification of the Genomic Library in $\mathrm{pCRTM} 8 / \mathrm{GW} / \mathrm{TOPO}^{\circledR}$}

The donor plasmid library was transformed in E. coli Top10 cells (CBMSO Fermentation Facility, Madrid, Spain) using electroporation. Transformants were stored at $-80{ }^{\circ} \mathrm{C}$ in the presence of $10 \%(v / v)$ glycerol. The number of independent clones was determined as CFU on LB-Agar plates supplemented with $100 \mu \mathrm{g} / \mathrm{mL}$ spectinomycin. According to the expression given by Clarke and Carbon [83], the colony bank size that was needed to obtain a plasmid collection that covered B. thuringiensis HER1410 genome at least once with a probability of 0.95 and an average fragment size of $600 \mathrm{bp}$, taking into account the six possible reading frames, was $1.842 \times 10^{5} \mathrm{CFU}$. This number of clones was outreached along the construction of the library (Figure 1 ). The original genomic library was propagated in SeaPrep ${ }^{\circledR}$ (FMC) semisolid medium [84] to minimize the representational biases that can occur during the expansion of plasmid DNA libraries [85]. The total number of clones was titered again via serial dilutions and plating on selective LB Agar plates. Then, $10^{7}$ cells were inoculated in $50 \mathrm{~mL}$ LB medium that was supplemented with $100 \mu \mathrm{g} / \mathrm{mL}$ spectinomycin and grown overnight at $37^{\circ} \mathrm{C}$ for purification of the plasmid library DNA via Miniprep (NucleoSpin Plasmid, Macherey-Nagel). The efficiency of the fragment insertion $(100 \%)$ was checked using plasmid purification of 15 clones, followed by digestion with EcoRI-HF (Supplementary Figure S8A) and sequencing (Supplementary Figure S8C) with the forward primer GW1 (Supplementary Table S7).

\subsubsection{Subcloning of the Library in the $\mathrm{Y} 2 \mathrm{H}$ Expression Vectors}

Using $50 \mathrm{ng}$ of the pCR8/GW/TOPO library as donor plasmids, the inserts were subcloned into the pPC (pGADCg) and pPN (pGADT7g) plasmids using a Gateway ${ }^{\mathrm{TM}}$ LR Clonase $^{\mathrm{TM}}$ II Enzyme mix (ThermoFisher, Waltham USA), according to the manufacturer's instructions. The LR reaction product was used to transform Top10 cells, titer, and amplify, as detailed above (Figure 1). The LR reactions with pPC and pPN resulted in C-terminal and $\mathrm{N}$-terminal fusions of the Gal4p activation domain (AD) to the gateway cassettes respectively. The efficiency of insertion ( $85 \%$ for $\mathrm{pPC}$ and $100 \%$ for $\mathrm{pPN}$ ) was checked via plasmid purification of seven clones from each library, followed by PCR amplification (Supplementary Figure S8B). These fourteen clones were also verified via sequencing (Supplementary Figure S8C) using attB1 and T7_FW primers, respectively (Supplementary Table S7). The genomic libraries in the $\mathrm{pPC}$ and $\mathrm{pPN}$ prey vectors were purified using Miniprep, as detailed above.

\subsubsection{Transformation of Saccharomyces cerevisiae Y187 with the Y2H Genomic Libraries}

The $\mathrm{pPC}$ and pPN libraries were used to transform Saccharomyces cerevisiae strain Y187 via electroporation [86]. Transformants were titered to determine the number of independent clones (Figure 1) and the library was further expanded in $50150 \mathrm{~mm}$ Petri dishes with selective solid media without leucine. The grown cells were harvested in a liquid selective medium containing $25 \%$ glycerol for storage at $-80^{\circ} \mathrm{C}$. Prior to the mating experiments, the final libraries were titered on selective media, and their genome coverage was analyzed using high-throughput sequencing (see below).

\subsection{Yeast Two-Hybrid Screening}

We designed a multiple yeast two-hybrid screening with a collection of 80 bait vectors, previously characterized in Berjón-Otero et al. [19], that included C-terminal (pBC (pGBKCg)) and N-terminal (pBN (pGBGT7g)) fusions of the Gal4p DNA-binding domain (DBD) to all the 32 Bam35 ORFs plus six variants without terminal transmembrane do- 
mains, as well as the empty $\mathrm{pBC}$ and pBN vectors. Each of the bait vectors was tested against the prey HER1410 libraries in the $\mathrm{pPC}$ and $\mathrm{pPN}$ vectors, yielding a total number of 158 mating experiments. Since it was not possible to obtain the Bam35 ORF16 pPC construct, this vector was not included in the screen [19]. Mating experiments were performed between AH109 yeast cells harboring pBC or pBN with the Bam35 ORFs (bait) and Y187 yeast cells harboring the pPC or pPN libraries, as described in Mehla et al. [87], with specific modifications for the subsequent HTS analysis (see the next section). Briefly, $4 \mathrm{~mL}$ of the bait and prey cultures at an $\mathrm{OD}_{600}$ of $0.8-1$ were mixed before harvesting the cells via centrifugation. The cells were subsequently plated on rich solid media (YPDA plates) to allow for mating. After overnight incubation at RT, the cells were harvested, washed, and resuspended in $2 \mathrm{~mL}$ of selective liquid media lacking leucine, tryptophan, and histidine (-LWH). To perform the interaction selection, HIS3, coding for an imidazole glycerol phosphate dehydratase that is necessary for histidine biosynthesis, was used as a reporter gene. In short, $100 \mu \mathrm{L}$ of the resuspended cells were plated on selective solid media (-LWH) that was supplemented with 3-amino-triazole (3AT). To avoid self-activation via DBD-fusion proteins, each screen was performed in the presence of the 3AT concentration that was determined for each bait [19]. To measure the efficiency of mating, the culture was diluted $1: 10^{5}$ and plated on diploid selective solid media without leucine and tryptophan. Moreover, to remove the background and further confirm the positive clones, we made two stamp replicas on triple dropout media in the presence of $\mathrm{X}-\alpha-\mathrm{Gal}$. Blue colonies show positive interactions for two markers, HIS3 and MEL1. In some cases, the screen gave rise to a lawn of cells. 3AT was increased for those screens to reduce the number of false positives (Supplementary Figure S4A). Finally, Y2H-positive colonies, i.e., yeast cells that were capable of growing on the triple-dropout media, from the last replica of each $\mathrm{Y} 2 \mathrm{H}$ screen were pooled and harvested for further HTS analysis. Additionally, to validate the HTS results (see below), we randomly picked single colonies of the final replicas before harvesting. As such, we randomly analyzed 70 colonies, including all combinations (pBCpPC, pBC-pPN, pBN-pPC, pBN-pPN) whose prey inserts were identified using colony PCR followed by Sanger sequencing (Supplementary Table S9).

\subsection{Genomic Library and Y2H Positives Analyses Using High-Throughput Sequencing 4.5.1. pPC and pPN Libraries Sequencing}

Validation of the HER1410 genomic libraries was achieved by sequencing each of the plasmid libraries, namely, pPC and pPN, purified from the yeast strain Y187 with the Zymoprep Yeast Plasmid Miniprep Kit (Zymo Research, Irvine, USA). Plasmid isolation from yeast cells typically yields very low amounts of DNA. As such, the purified plasmid libraries were used to amplify the genomic inserts using tailed-PCR (Supplementary Figure S8D) with the forward primers attB1_HTS for the pPC library and T7_HTS for the pPN library and the reverse primer attb2_HTS (Supplementary Table S7). To ensure faithful and proportional amplification of each fragment, Q5 High-Fidelity DNA Polymerase (New England Biolabs, Ipswich, USAE) was used, and the number of amplification cycles was limited to 20. Secondary PCR amplification was subsequently performed using the HTS Unit from the "Parque Científico de Madrid" to generate Illumina sequencing libraries. The PCR products were sequenced using a single Illumina MiSeq $300 \mathrm{bp}$ paired-end run in this facility. The total raw reads that were obtained from the libraries sequencing represented an average coverage of the original genome $(6,147,475 \mathrm{bp})$ of $260 \times$ for the pPC library and $234.5 \times$ for the pPN library. Prior to the construction of the Illumina sequencing libraries, the fragments were analyzed using agarose electrophoresis. The Illumina sequencing libraries were analyzed using microchip electrophoresis on an Agilent 2100 Bioanalyzer using DNA 7500 Assay Kit (Agilent Technologies, Santa Clara, USA).

\subsubsection{Y2H Positives Preparation and Sequencing}

The Y2H-positive colonies from the last replica of each $\mathrm{Y} 2 \mathrm{H}$ assay were pooled and harvested. This resulted in 156 samples, one per mating experiment. To identify the interacting 
prey partners for each sample, plasmid DNA was purified via yeast miniprep in multi-well MW96 format (Zymoprep-96 Yeast Plasmid Miniprep). Then, the HER1410 fragments were low-cycle, tailed PCR-amplified using Q5 High-Fidelity DNA Polymerase, as explained above, with the specific forward primers pPC and pPN and the reverse primer attB2_HTS (Supplementary Table S7). Moreover, each sample was confirmed using PCR with specific oligonucleotides for the corresponding viral bait gene. Finally, PCR products were sent to the HTS facility to construct barcoded Illumina libraries, which were sequenced in a single Illumina MiSeq 300 bp paired-end run to obtain about 15,000 reads per sample. Fragments were analyzed using agarose electrophoresis prior to the construction of Illumina sequencing libraries. Illumina sequencing libraries were analyzed using microchip electrophoresis on an Agilent 2100 Bioanalyzer using DNA 7500 Assay Kit (Agilent Technologies). The samples containing fragments shorter than $300 \mathrm{bp}$ were split ( $<300 \mathrm{bp}$ and $>300 \mathrm{bp}$ ) and sequenced independently to avoid sequencing bias.

\subsubsection{Trimming, Quality Check, and Mapping of Illumina Reads}

The Illumina reads were verified for quality using FastQC v0.11.8 and Trimmomatic v0.38 was used to exclude reads shorter than $185 \mathrm{bp}[88,89]$. To remove primers and plasmid sequences from the reads, a clipping step based on sequence size was performed using seqtk [90]. The first 39 and 139 nucleotides of R1 reads of the pPC and pPN libraries, respectively, and the first 38 nucleotides of $\mathrm{R} 2$ reads were removed. For the seqtk clipping of the $\mathrm{Y} 2 \mathrm{H}$ positive sequences, the first 99 and 59 nucleotides of the $\mathrm{R} 1$ reads from the $\mathrm{pPC}$ and pPN sequences, respectively, and the last 38 nucleotides of the R2 reads were removed. FastQC reports of raw and processed reads were consolidated using MultiQC v1.9 [91]. To extract the in-frame HER1410 fragments, a custom bioinformatics pipeline was set up (Figure 2). Briefly, reads that did not start with the starting codon "ATG" were removed. These "ATG" sites corresponded to the prey fragment ends that were generated by partial digestion with CviAII, cloned in frame with the destination vectors. Subsequently, using the R1 and R2 reads, the prey fragments were reconstructed and clustered, generating a database of unique fragments. Clustering was performed using CDhit software at 100\% sequence identity level and identical length [92]. The unique fragments were then translated and searched in the HER1410 proteome using BLASTp [93]. Fragments resulting in a BLASTp hit longer than ten amino acids were kept as "in-frame unique fragments." To obtain the frequency for each unique fragment, clusters reconstruction was performed, resulting in the number of reads for each unique fragment. Additionally, results were manually curated to eliminate the fragments containing a stop codon or that were not in frame with the AD domain in $\mathrm{pPC}$, and the hits after a stop codon in $\mathrm{pPN}$, generating our $\mathrm{Y} 2 \mathrm{H}$-validated fragments database. The bioinformatics pipeline is available on github: https://github.com/LoGT-KULeuven/y2h_Bam35-Bt_analysis (last accessed 12 October 2021).

\subsubsection{Evaluation of Genomic Library Quality}

Genomic library statistics were analyzed using Excel software (Microsoft). The nucleotide coverage of the total fragments was calculated using bwa-mem [94] and samtools [95], and visualized with weeSAM version 1.5 (last accessed 12 October 2021 at https://bioinformatics.cvr.ac.uk/weesam-version-1-5/).

\subsubsection{Evaluation of Raw Y2H Interactions}

The mapping of positive interactions reads resulted in the identification of 4477 possible interactions (Supplementary Table S3). The filtering of these raw results was performed to improve the specificity of the putative protein interaction set by applying a set of sequential filtering steps to the data. First, the number of reads corresponding to each interaction was normalized to the total reads in the sample. This normalized number was used as a measure of enrichment of the prey fragment in the corresponding combination and, therefore, of the strength of the interaction. Thus, this value was used to establish the 
enrichment categories according to the distribution of the positive hits (Supplementary Figure S11). The dataset was divided into three categories: C for interactions with $0-0.25 \%$ of abundance, B for $0.25-10 \%$, and A for $10-100 \%$. Only the most abundant interactions (categories A and B) were considered for further analysis. Second, prey fragments that interacted with a large number of baits were tagged as potential promiscuous or "sticky prey" (Supplementary Table S4). Thus, interactions involving HER1410 protein fragments that interacted with more than six different Bam 35 proteins, which was the average number of interactors after selection, were excluded from further evaluation. Third, prey interacting partners of bait pBC and pBN empty plasmids were considered as false-positive generating prey. Interactions involving these prey plasmids were also removed from the dataset (Supplementary Table S5). Last, duplicated interactions that came from the under and over 300 bp sequencing runs were consolidated. Finally, the obtained putative PPIs that resulted from the dataset filtering were analyzed and represented as interaction maps with Cytoscape software [96].

Descriptive and comparative analysis of the positive interactions reads dataset (Supplementary Table S2) was performed with SPSS ${ }^{\circledR}$ Statistics software (IBM). Linear correlations analysis between library fragments and interacting fragments reads abundance was performed with the ggplot package for R software [97].

\subsection{Full-Length Protein Pairwise Y2H Assays}

A total of 33 putative interactions were re-screened using complete host proteins and their viral partners (Table 3). In total, 15 interactions from category $\mathrm{A}$ and 18 interactions from category $B$ were selected at random and retested with the full-length host proteins. The $B$. thuringiensis HER1410 purified genomic DNA was used to amplify the selected ORFs with PCR using Q5 High-Fidelity DNA Polymerase and ORF-specific primers (Supplementary Table S7). These primers were designed using Geneious software [98], ensuring the presence of 20 to 30 nucleotides that were complementary to the ORF of interest and removing endogenous stop codons. The attB1 and attB2 sequences were added at the $5^{\prime}$ end of the forward and reverse primers, respectively. As described in Berjón-Otero et al. [19], tail PCR products were cloned into the entry vector pDONR/Zeo (Invitrogen) and subsequently subcloned into the corresponding prey vectors $\mathrm{pPC}$ and pPN. All vectors that were obtained from the cloning and subcloning steps were tested using colony PCR with ORF-specific primers. The insertion of the ORFs into the entry and expression vectors was also verified using sequencing. The expression vectors were used to transform S. cerevisiae Y187 following the heat-shock transformation protocol described in Mehla et al. [87]. Transformants containing prey vectors were selected on a solid medium without leucine and checked with colony PCR using pPC_HTS or pPN_HTS forward primers and the corresponding ORF-specific reverse primer (Suppementary Table S9).

Pairwise screens of the selected interactions were performed, as detailed in Table 3 , using the bait vectors $\mathrm{pBC}$ and $\mathrm{pBN}$ containing the Bam 35 ORFs that were characterized in Berjón-Otero et al. [19] and the obtained pPC and pPN prey vectors containing the selected HER1410 ORFs. We performed mating between yeast cells containing bait vectors and cells containing prey vectors on rich solid media (YPDA plates), including the correspondent self-activation controls with the empty vectors. Diploid cells were selected on a solid medium without leucine and tryptophan. Finally, to detect protein-protein interactions, HIS3 was used as a reporter gene. For this, the obtained diploid cells were plated on selective solid media without leucine, tryptophan, and histidine and supplemented with different 3AT concentrations $(0,0.025,0.1,3,10,25,50$, and $100 \mathrm{mM})$. When the yeast growth was higher in the Bt-B35 combination than in the self-activation controls, this interaction was considered positive. 
Supplementary Materials: The following are available online at https://www.mdpi.com/article/10.3 390/ijms222011105/s1.

Author Contributions: Conceptualization, M.R.-R.; methodology, A.L., M.B.-O., C.L. and M.R.-R.; software, C.L.; formal analysis, A.L., C.L. and M.R.-R.; investigation, A.L., C.L., A.d.P. and J.W.; resources, R.L. and M.S.; data curation, A.L. and C.L.; writing-original draft preparation, A.L. and M.R.-R.; writing-review and editing, A.L., C.L., J.W., V.v.N., R.L. and M.R.-R.; supervision, V.v.N., R.L., M.S. and M.R.-R.; funding acquisition, R.L., M.S. and M.R.-R. All authors have read and agreed to the published version of the manuscript.

Funding: This work was funded by a grant from Fundación Ramón Areces (VirHostOmics). A.L. was the holder of a Ph.D. fellowship (FPU15/05797) from the Spanish Ministry of Science, Innovation and Universities. C.L. is supported by a Ph.D. fellowship from FWO Vlaanderen (1S64720N). V.v.N. and R.L. are supported by the C1-grant "ACES" from KU Leuven.

Institutional Review Board Statement: Not applicable.

Informed Consent Statement: Not applicable.

Data Availability Statement: All sequencing data were deposited in the NCBI SRA database and is accessible via the BioProject PRJNA717632, or directly via the sample accession numbers listed in Supplementary Table S2. The Bam35-B. thuringiensis high-quality interactions reported in Supplementary Table S6 were also deposited in the Database of Interacting Proteins under the IMEx Consortium dataset identifier IM-28933.

Acknowledgments: We would like to thank the Genomics and Massive Sequencing facility of CBMSO for their technical assistance in the early stages of this project. An institutional grant from Fundación Ramón Areces and Banco Santander to the Centro de Biología Molecular Severo Ochoa is also acknowledged.

Conflicts of Interest: The authors declare no conflict of interest.

\section{References}

1. Oksanen, H.M.; Bamford, D.H. Family Tectiviridae. In Virus Taxonomy: Ninth Report of the International Committee on Taxonomy of Viruses, 2012th ed.; Andrew, M.Q., King, M.J.A., Carstens, E.B., Lefkowitz, E.J., Eds.; Elsevier, Academic Press: San Diego, CA, USA, 2012. Available online: https://talk.ictvonline.org/ictv-reports/ictv_online_report/ (accessed on 12 October 2021).

2. Caruso, S.M.; deCarvalho, T.N.; Erill, I.; Gill, J.J.; Gillis, A. Taxonomic Proposal 2020.042B.R Create Two New Genera (Deltatectivirus and Epsilontectivirus) Including Three New Species (Kalamavirales: Tectiviridae). 2021. Available online: https://talk.ictvonline. org/files/ictv_official_taxonomy_updates_since_the_8th_report/m/prokaryote-official/12150 (accessed on 12 October 2021).

3. Yutin, N.; Bäckström, D.; Ettema, T.J.G.; Krupovic, M.; Koonin, E.V. Vast diversity of prokaryotic virus genomes encoding double jelly-roll major capsid proteins uncovered by genomic and metagenomic sequence analysis. Virol. J. 2018, 15, 1-17. [CrossRef] [PubMed]

4. Caruso, S.M.; Decarvalho, T.N.; Huynh, A.; Morcos, G.; Kuo, N.; Parsa, S.; Erill, I. A Novel Genus of Actinobacterial Tectiviridae. Viruses 2019, 11, 1134. [CrossRef] [PubMed]

5. Krupovic, M.; Prangishvili, D.; Hendrix, R.W.; Bamford, D.H. Genomics of Bacterial and Archaeal Viruses: Dynamics within the Prokaryotic Virosphere. Microbiol. Mol. Biol. Rev. 2011, 75, 610-635. [CrossRef] [PubMed]

6. Krupovic, M.; Koonin, E.V. Polintons: A hotbed of eukaryotic virus, transposon and plasmid evolution. Nat. Rev. Microbiol. 2014, 13, 105-115. [CrossRef]

7. Jalasvuori, M.; Koskinen, K. Extending the hosts of Tectiviridae into four additional genera of Gram-positive bacteria and more diverse Bacillus species. Virology 2018, 518, 136-142. [CrossRef]

8. Kan, S.; Fornelos, N.; Schuch, R.; Fischetti, V.A. Identification of a Ligand on the Wip1 Bacteriophage Highly Specific for a Receptor on Bacillus anthracis. J. Bacteriol. 2013, 195, 4355-4364. [CrossRef]

9. Sozhamannan, S.; McKinstry, M.; Lentz, S.M.; Jalasvuori, M.; McAfee, F.; Smith, A.; Dabbs, J.; Ackermann, H.-W.; Bamford, J.K.H.; Mateczun, A.; et al. Molecular Characterization of a variant of Bacillus anthracis-specific phage AP50 with improved bacteriolytic activity. Appl. Environ. Microbiol. 2008, 74, 6792-6796. [CrossRef]

10. Gillis, A.; Mahillon, J. Phages Preying on Bacillus anthracis, Bacillus cereus, and Bacillus thuringiensis: Past, Present and Future. Viruses 2014, 6, 2623-2672. [CrossRef]

11. Ravantti, J.J.; Gaidelyte, A.; Bamford, D.H.; Bamford, J.K. Comparative analysis of bacterial viruses Bam35, infecting a grampositive host, and PRD1, infecting gram-negative hosts, demonstrates a viral lineage. Virology 2003, 313, 401-414. [CrossRef]

12. Laurinmäki, P.; Huiskonen, J.; Bamford, D.; Butcher, S. Membrane Proteins Modulate the Bilayer Curvature in the Bacterial Virus Bam35. Structure 2005, 13, 1819-1828. [CrossRef] 
13. Otero, M.B.; Villar, L.; Salas, M.; Redrejo-Rodríguez, M. Disclosing early steps of protein-primed genome replication of the Gram-positive tectivirus Bam35. Nucleic Acids Res. 2016, 44, 9733-9744. [CrossRef]

14. Ackermann, H.-W.; Roy, R.; Martin, M.; Murthy, M.R.V.; Smirnoff, W.A. Partial characterization of a cubic Bacillus phage. Can. J. Microbiol. 1978, 24, 986-993. [CrossRef] [PubMed]

15. Palma, L.; Muñoz, D.; Berry, C.; Murillo, J.; Caballero, P. Bacillus thuringiensis Toxins: An Overview of Their Biocidal Activity. Toxins 2014, 6, 3296-3325. [CrossRef]

16. Sanchis, V. From microbial sprays to insect-resistant transgenic plants: History of the biospesticide Bacillus thuringiensis. A review. Agron. Sustain. Dev. 2010, 31, 217-231. [CrossRef]

17. Gillis, A.; Mahillon, J. Prevalence, Genetic Diversity and Host Range of Tectiviruses among Members of the Bacillus cereus Group. Appl. Environ. Microbiol. 2014, 80, 4138-4152. [CrossRef] [PubMed]

18. Fornelos, N.; Butala, M.; Hodnik, V.; Anderluh, G.; Bamford, J.K.; Salas, M. Bacteriophage GIL01 gp7 interacts with host LexA repressor to enhance DNA binding and inhibit RecA-mediated auto-cleavage. Nucleic Acids Res. 2015, 43, 7315-7329. [CrossRef] [PubMed]

19. Berjón-Otero, M.; Lechuga, A.; Mehla, J.; Uetz, P.; Salas, M.; Redrejo-Rodríguez, M. Bam35 Tectivirus Intraviral Interaction Map Unveils New Function and Localization of Phage ORFan Proteins. J. Virol. 2017, 91, e00870-17. [CrossRef]

20. Laurinavičius, S.; Käkelä, R.; Somerharju, P.; Bamford, D.H. Phospholipid molecular species profiles of tectiviruses infecting Gram-negative and Gram-positive hosts. Virology 2004, 322, 328-336. [CrossRef]

21. Verheust, C.; Fornelos, N.; Mahillon, J.; Verheust, C. The Bacillus thuringiensis phage GIL01 encodes two enzymes with peptidoglycan hydrolase activity. FEMS Microbiol. Lett. 2004, 237, 289-295. [CrossRef]

22. Gaidelytè, A.; Cvirkaitè-Krupovic, V.; Daugelavicius, R.; Bamford, J.K.H.; Bamford, D.H. The Entry Mechanism of MembraneContaining Phage Bam35 Infecting Bacillus thuringiensis. J. Bacteriol. 2006, 188, 5925-5934. [CrossRef] [PubMed]

23. Grahn, A.M.; Daugelavicius, R.; Bamford, D.H. Sequential model of phage PRD1 DNA delivery: Active involvement of the viral membrane. Mol. Microbiol. 2002, 46, 1199-1209. [CrossRef]

24. Salas, M.; de Vega, M. Protein-Primed Replication of Bacteriophage $\Phi 29$ DNA. Enzymes 2016, 39, 137-167. [CrossRef]

25. Otero, M.B.; Villar, L.; de Vega, M.; Salas, M.; Redrejo-Rodríguez, M. DNA polymerase from temperate phage Bam35 is endowed with processive polymerization and abasic sites translesion synthesis capacity. Proc. Natl. Acad. Sci. USA 2015, 112, E3476-E3484. [CrossRef]

26. Verheust, C.; Jensen, G.; Mahillon, J. pGIL01, a linear tectiviral plasmid prophage originating from Bacillus thuringiensis serovar israelensis. Microbiology 2003, 149, 2083-2092. [CrossRef] [PubMed]

27. Fornelos, N.; Bamford, J.K.H.; Mahillon, J. Phage-Borne Factors and Host LexA Regulate the Lytic Switch in Phage GIL01. J. Bacteriol. 2011, 193, 6008-6019. [CrossRef]

28. Caveney, N.; Pavlin, A.; Caballero, G.; Bahun, M.; Hodnik, V.; De Castro, L.; Fornelos, N.; Butala, M.; Strynadka, N.C. Structural Insights into Bacteriophage GIL01 gp7 Inhibition of Host LexA Repressor. Structure 2019, 27, 1094-1102. [CrossRef]

29. Gillis, A.; Mahillon, J. Influence of Lysogeny of Tectiviruses GIL01 and GIL16 on Bacillus thuringiensis Growth, Biofilm Formation, and Swarming Motility. Appl. Environ. Microbiol. 2014, 80, 7620-7630. [CrossRef] [PubMed]

30. Fornelos, N.; Browning, D.F.; Pavlin, A.; Podlesek, Z.; Hodnik, V.; Salas, M.; Butala, M. Lytic gene expression in the temperate bacteriophage GIL01 is activated by a phage-encoded LexA homologue. Nucleic Acids Res. 2018, 46, 9432-9443. [CrossRef]

31. Gaidelytè, A.; Jaatinen, S.T.; Daugelavičius, R.; Bamford, J.K.H.; Bamford, D.H. The Linear Double-Stranded DNA of Phage Bam35 Enters Lysogenic Host Cells, but the Late Phage Functions Are Suppressed. J. Bacteriol. 2005, 187, 3521-3527. [CrossRef] [PubMed]

32. Beltran, P.J.; Federspiel, J.D.; Sheng, X.; Cristea, I.M. Proteomics and integrative omic approaches for understanding host-pathogen interactions and infectious diseases. Mol. Syst. Biol. 2017, 13, 922. [CrossRef]

33. Fields, S.; Song, O.-K. A novel genetic system to detect protein-protein interactions. Nature 1989, 340, 245-246. [CrossRef]

34. Bartel, P.L.; Roecklein, J.A.; Sengupta, D.; Fields, S. A protein linkage map of Escherichia coli bacteriophage T7. Nat. Genet. 1996, 12, 72-77. [CrossRef] [PubMed]

35. Roucourt, B.; Lecoutere, E.; Chibeu, A.; Hertveldt, K.; Volckaert, G.; Lavigne, R. A procedure for systematic identification of bacteriophage-host interactions of P. aeruginosa phages. Virology 2009, 387, 50-58. [CrossRef] [PubMed]

36. Blasche, S.; Wuchty, S.; Rajagopala, S.; Uetz, P. The Protein Interaction Network of Bacteriophage Lambda with Its Host, Escherichia coli. J. Virol. 2013, 87, 12745-12755. [CrossRef]

37. Wagemans, J.; Blasdel, B.; Bossche, A.V.D.; Uytterhoeven, B.; De Smet, J.; Paeshuyse, J.; Cenens, W.; Aertsen, A.; Uetz, P.; Delattre, A.-S.; et al. Functional elucidation of antibacterial phage ORFans targeting Pseudomonas aeruginosa. Cell. Microbiol. 2014, 16, 1822-1835. [CrossRef]

38. Mariano, R.; Wuchty, S.; Vizoso-Pinto, M.G.; Hauser, R.; Uetz, P. The interactome of Streptococcus pneumoniae and its bacteriophages show highly specific patterns of interactions among bacteria and their phages. Sci. Rep. 2016, 6, 24597. [CrossRef]

39. Mehla, J.; Dedrick, R.M.; Caufield, J.H.; Wagemans, J.; Sakhawalkar, N.; Johnson, A.; Hatfull, G.F.; Uetz, P. Virus-host proteinprotein interactions of mycobacteriophage Giles. Sci. Rep. 2017, 7, 16514. [CrossRef]

40. Häuser, R.; Blasche, S.; Dokland, T.; Haggård-Ljungquist, E.; von Brunn, A.; Salas, M.; Casjens, S.; Molineux, I.; Uetz, P. Bacteriophage Protein-Protein Interactions. Adv. Virus Res. 2012, 83, 219-298. [CrossRef] 
41. Bossche, A.V.D.; Ceyssens, P.-J.; De Smet, J.; Hendrix, H.; Bellon, H.; Leimer, N.; Wagemans, J.; Delattre, A.-S.; Cenens, W.; Aertsen, A.; et al. Systematic Identification of Hypothetical Bacteriophage Proteins Targeting Key Protein Complexes of Pseudomonas aeruginosa. J. Proteome Res. 2014, 13, 4446-4456. [CrossRef] [PubMed]

42. Mariano, R.; Khuri, S.; Uetz, P.; Wuchty, S. Local Action with Global Impact: Highly Similar Infection Patterns of Human Viruses and Bacteriophages. mSystems 2016, 1, e00030-15. [CrossRef]

43. Yachie, N.; Petsalaki, E.; Mellor, J.C.; Weile, J.; Jacob, Y.; Verby, M.; Ozturk, S.B.; Li, S.; Cote, A.G.; Mosca, R.; et al. Pooled-matrix protein interaction screens using Barcode Fusion Genetics. Mol. Syst. Biol. 2016, 12, 863. [CrossRef]

44. Trigg, S.; Garza, R.M.; MacWilliams, A.; Nery, J.R.; Bartlett, A.; Castanon, R.; Goubil, A.; Feeney, J.; O’Malley, R.; Huang, S.-S.C.; et al. CrY2H-seq: A massively multiplexed assay for deep-coverage interactome mapping. Nat. Methods 2017, 14, 819-825. [CrossRef]

45. Yang, J.-S.; Garriga-Canut, M.; Link, N.; Carolis, C.; Broadbent, K.; Beltran-Sastre, V.; Serrano, L.; Maurer, S.P. rec-YnH enables simultaneous many-by-many detection of direct protein-protein and protein-RNA interactions. Nat. Commun. 2018, 9, 1-13. [CrossRef] [PubMed]

46. Lewis, J.D.; Wan, J.; Ford, R.; Gong, Y.; Fung, P.; Nahal, H.; Wang, P.W.; Desveaux, D.; Guttman, D.S. Quantitative Interactor Screening with next-generation Sequencing (QIS-Seq) identifies Arabidopsis thaliana MLO2 as a target of the Pseudomonas syringae type III effector HopZ2. BMC Genom. 2012, 13, 8. [CrossRef] [PubMed]

47. Erffelinck, M.-L.; Ribeiro, B.; Perassolo, M.; Pauwels, L.; Pollier, J.; Storme, V.; Goossens, A. A user-friendly platform for yeast two-hybrid library screening using next generation sequencing. PLoS ONE 2018, 13, e0201270. [CrossRef] [PubMed]

48. Mehla, J.; Caufield, J.; Sakhawalkar, N.; Uetz, P. A Comparison of Two-Hybrid Approaches for Detecting Protein-Protein Interactions. Methods Enzymol. 2017, 586, 333-358. [CrossRef]

49. Gonzales, T.; Robert-Baudouy, J. Bacterial aminopeptidases: Properties and functions. FEMS Microbiol. Rev. 1996, 18, 319-344. [CrossRef]

50. Lechuga, A.; Kazlauskas, D.; Salas, M.; Redrejo-Rodríguez, M. Unlimited Cooperativity of Betatectivirus SSB, a Novel DNA Binding Protein Related to an Atypical Group of SSBs from Protein-Primed Replicating Bacterial Viruses. Front. Microbiol. 2021, 12, 699140. [CrossRef]

51. Rajagopala, S.V.; Yamamoto, N.; Zweifel, A.E.; Nakamichi, T.; Huang, H.-K.; Mendez-Rios, J.D.; Franca-Koh, J.; Boorgula, M.P.; Fujita, K.; Suzuki, K.-I.; et al. The Escherichia coli K-12 ORFeome: A resource for comparative molecular microbiology. BMC Genom. 2010, 11, 470. [CrossRef]

52. Andrews, S.S.; Schaefer-Ramadan, S.; Al-Thani, N.; Ahmed, I.; Mohamoud, Y.A.; Malek, J.A. High-resolution protein-protein interaction mapping using all-versus-all sequencing (AVA-Seq). J. Biol. Chem. 2019, 294, 11549-11558. [CrossRef]

53. Lechuga, A.; Lood, C.; Salas, M.; van Noort, V.; Lavigne, R.; Redrejo-Rodríguez, M. Completed Genomic Sequence of Bacillus thuringiensis HER1410 Reveals a Cry-Containing Chromosome, Two Megaplasmids, and an Integrative Plasmidial Prophage. G3 Genes Genomes Genet. 2020, 10, 2927-2939. [CrossRef]

54. Maier, R.H.; Brandner, C.J.; Hintner, H.; Bauer, J.W.; Önder, K. Construction of a reading frame-independent yeast two-hybrid vector system for site-specific recombinational cloning and protein interaction screening. BioTechniques 2008, 45, 235-244. [CrossRef]

55. Yang, F.; Lei, Y.; Zhou, M.; Yao, Q.; Han, Y.; Wu, X.; Zhong, W.; Zhu, C.; Xu, W.; Tao, R.; et al. Development and application of a recombination-based library versus library high- throughput yeast two-hybrid (RLL-Y2H) screening system. Nucleic Acids Res. 2017, 46, e17. [CrossRef]

56. Caufield, J.H.; Sakhawalkar, N.; Uetz, P. A comparison and optimization of yeast two-hybrid systems. Methods 2012, 58, 317-324. [CrossRef]

57. Stellberger, T.; Häuser, R.; Baiker, A.; Pothineni, V.R.; Haas, J.; Uetz, P. Improving the yeast two-hybrid system with permutated fusions proteins: The Varicella Zoster Virus interactome. Proteome Sci. 2010, 8, 8. [CrossRef]

58. Rajagopala, S.; Sikorski, P.; Kumar, A.; Mosca, R.; Vlasblom, J.; Arnold, R.; Franca-Koh, J.; Pakala, S.; Phanse, S.; Ceol, A.; et al. The binary protein-protein interaction landscape of Escherichia coli. Nat. Biotechnol. 2014, 32, 285-290. [CrossRef]

59. Wuchty, S.; Rajagopala, S.V.; Blazie, S.M.; Parrish, J.R.; Khuri, S.; Finley, R.; Uetz, P. The Protein Interactome of Streptococcus pneumoniae and Bacterial Meta-interactomes Improve Function Predictions. mSystems 2017, 2, e00019-17. [CrossRef]

60. Suter, B.; Zhang, X.; Pesce, C.G.; Mendelsohn, A.R.; Dinesh-Kumar, S.P.; Mao, J.-H. Next-Generation Sequencing for Binary Protein-Protein Interactions. Front. Genet. 2015, 6, 346. [CrossRef] [PubMed]

61. Brückner, A.; Polge, C.; Lentze, N.; Auerbach, D.; Schlattner, U. Yeast Two-Hybrid, a Powerful Tool for Systems Biology. Int. J. Mol. Sci. 2009, 10, 2763-2788. [CrossRef]

62. Weimann, M.; Grossmann, A.; Woodsmith, J.; Özkan, Z.; Birth, P.; Meierhofer, D.; Benlasfer, N.; Valovka, T.; Timmermann, B.; Wanker, E.; et al. A Y2H-seq approach defines the human protein methyltransferase interactome. Nat. Methods 2013, 10, 339-342. [CrossRef] [PubMed]

63. Gillis, A.; Fayad, N.; Makart, L.; Bolotin, A.; Sorokine, A.; Kallassy, M.; Mahillon, J. Role of plasmid plasticity and mobile genetic elements in the entomopathogen Bacillus thuringiensis serovar israelensis. FEMS Microbiol. Rev. 2018, 42, 829-856. [CrossRef]

64. Pfeifer, E.; Sousa, J.A.M.D.; Touchon, M.; Rocha, E.P.C. Bacteria have numerous distinctive groups of phage-plasmids with conserved phage and variable plasmid gene repertoires. Nucleic Acids Res. 2021, 49, 2655-2673. [CrossRef] [PubMed]

65. Pelchovich, G.; Omer-Bendori, S.; Gophna, U. Menaquinone and Iron Are Essential for Complex Colony Development in Bacillus subtilis. PLoS ONE 2013, 8, e79488. [CrossRef] 
66. Madeira, J.-P.; Omer, H.; Alpha-Bazin, B.; Armengaud, J.; Duport, C. Deciphering the interactions between the Bacillus cereus linear plasmid, pBClin15, and its host by high-throughput comparative proteomics. J. Proteom. 2016, 146, 25-33. [CrossRef]

67. Poranen, M.; Ravantti, J.J.; Grahn, A.M.; Gupta, R.; Auvinen, P.; Bamford, D.H. Global Changes in Cellular Gene Expression during Bacteriophage PRD1 Infection. J. Virol. 2006, 80, 8081-8088. [CrossRef] [PubMed]

68. Mojardín, L.; Salas, M. Global Transcriptional Analysis of Virus-Host Interactions between Phage $\phi 29$ and Bacillus subtilis. J. Virol. 2016, 90, 9293-9304. [CrossRef]

69. Leskinen, K.; Blasdel, B.G.; Lavigne, R.; Skurnik, M. RNA-Sequencing Reveals the Progression of Phage-Host Interactions between $\varphi$ R1-37 and Yersinia enterocolitica. Viruses 2016, 8, 111. [CrossRef] [PubMed]

70. Lood, C.; Danis-Wlodarczyk, K.; Blasdel, B.G.; Bin Jang, H.; Vandenheuvel, D.; Briers, Y.; Noben, J.; van Noort, V.; Drulis-Kawa, Z.; Lavigne, R. Integrative omics analysis of Pseudomonas aeruginosa virus PA5oct highlights the molecular complexity of jumbo phages. Environ. Microbiol. 2020, 22, 2165-2181. [CrossRef]

71. Szklarczyk, D.; Gable, A.L.; Lyon, D.; Junge, A.; Wyder, S.; Huerta-Cepas, J.; Simonovic, M.; Doncheva, N.T.; Morris, J.H.; Bork, P.; et al. STRING v11: Protein-protein association networks with increased coverage, supporting functional discovery in genome-wide experimental datasets. Nucleic Acids Res. 2018, 47, D607-D613. [CrossRef]

72. Brombacher, E.; Dorel, C.; Zehnder, A.J.B.; Landini, P. The curli biosynthesis regulator CsgD co-ordinates the expression of both positive and negative determinants for biofilm formation in Escherichia coli. Microbiology 2003, 149, 2847-2857. [CrossRef]

73. Mattila, S.; Oksanen, H.M.; Bamford, J.K.H. Probing protein interactions in the membrane-containing virus PRD1. J. Gen. Virol. 2015, 96, 453-462. [CrossRef]

74. Rydman, P.S.; Bamford, D.H. Identification and Mutational Analysis of Bacteriophage PRD1 Holin Protein P35. J. Bacteriol. 2003, 185, 3795-3803. [CrossRef] [PubMed]

75. Hänninen, A.-L.; Bamford, D.H.; Bamford, J.K. Assembly of Membrane-Containing Bacteriophage PRD1 Is Dependent on GroEL and GroES. Virology 1997, 227, 207-210. [CrossRef]

76. Clair, G.; Roussi, S.; Armengaud, J.; Duport, C. Expanding the Known Repertoire of Virulence Factors Produced by Bacillus cereus through Early Secretome Profiling in Three Redox Conditions. Mol. Cell. Proteom. 2010, 9, 1486-1498. [CrossRef] [PubMed]

77. Kamitori, S.; Yoshida, H. Structure-Function Relationship of Bacterial SH3 Domains. In SH Domains: Structure, Mechanisms and Applications; Kurochkina, N., Ed.; Springer International Publishing: Cham, Switzerland, 2015; pp. 71-89. [CrossRef]

78. Jalasvuori, M.; Palmu, S.; Gillis, A.; Kokko, H.; Mahillon, J.; Bamford, J.K.; Fornelos, N. Identification of five novel tectiviruses in Bacillus strains: Analysis of a highly variable region generating genetic diversity. Res. Microbiol. 2013, 164, 118-126. [CrossRef]

79. Charlier, D.; Gh, G.H.; Kholti, A.; Gigot, D.; Piérard, A.; Glansdorff, N. carP, Involved in Pyrimidine Regulation of the Escherichia coli Carbamoylphosphate Synthetase Operon Encodes a Sequence-specific DNA-binding Protein Identical to XerB and PepA, also Required for Resolution of ColEl Multimers. J. Mol. Biol. 1995, 250, 392-406. [CrossRef] [PubMed]

80. Moses, S.; Sinner, T.; Zaprasis, A.; Stöveken, N.; Hoffmann, T.; Belitsky, B.R.; Sonenshein, A.L.; Bremer, E. Proline Utilization by Bacillus subtilis: Uptake and Catabolism. J. Bacteriol. 2012, 194, 745-758. [CrossRef]

81. James, P.; Halladay, J.; Craig, E.A. Genomic Libraries and a Host Strain Designed for Highly Efficient Two-Hybrid Selection in Yeast. Genetics 1996, 144, 1425-1436. [CrossRef]

82. Green, M.R.; Sambrook, J. Precipitation of DNA with Ethanol. Cold Spring Harb. Protoc. 2016, 2016. [CrossRef]

83. Clarke, L.; Carbon, J. A colony bank containing synthetic CoI EI hybrid plasmids representative of the entire E. coli genome. Cell 1976, 9, 91-99. [CrossRef]

84. Elsaesser, R.; Paysan, J. Liquid gel amplification of complex plasmid libraries. BioTechniques 2004, 37, 200-202. [CrossRef]

85. Kriegler, M. Gene Transfer and Expression: A Laboratory Manual; Springer: Berlin/Heidelberg, Germany, 1990.

86. Benatuil, L.; Perez, J.M.; Belk, J.; Hsieh, C.-M. An improved yeast transformation method for the generation of very large human antibody libraries. Protein Eng. Des. Sel. 2010, 23, 155-159. [CrossRef]

87. Mehla, J.; Caufield, J.H.; Uetz, P. Mapping Protein-Protein Interactions Using Yeast Two-Hybrid Assays. Cold Spring Harb. Protoc. 2015, 2015, pdb-prot086157. [CrossRef] [PubMed]

88. Andrews, S. FastQC: A quality control tool for high throughput sequence data. In Babraham Bioinformatics; Babraham Institute: Cambridge, UK, 2010.

89. Bolger, A.M.; Lohse, M.; Usadel, B. Trimmomatic: A flexible trimmer for Illumina sequence data. Bioinformatics 2014, 30, 2114-2120. [CrossRef] [PubMed]

90. Seqtk. Available online: https://github.com/lh3/seqtk (accessed on 25 October 2020).

91. Ewels, P.; Magnusson, M.; Lundin, S.; Käller, M. MultiQC: Summarize analysis results for multiple tools and samples in a single report. Bioinformatics 2016, 32, 3047-3048. [CrossRef]

92. Fu, L.; Niu, B.; Zhu, Z.; Wu, S.; Li, W. CD-HIT: Accelerated for clustering the next-generation sequencing data. Bioinformatics 2012, 28, 3150-3152. [CrossRef] [PubMed]

93. Wheeler, D.L.; Barrett, T.; Benson, D.A.; Bryant, S.H.; Canese, K.; Chetvernin, V.; Church, D.M.; DiCuccio, M.; Edgar, R.; Federhen, S.; et al. Database resources of the National Center for Biotechnology Information. Nucleic Acids Res. 2006, 35, D5-D12. [CrossRef]

94. Li, H. BWA-MEM. Available online: https://github.com/lh3/bwa (accessed on 12 October 2021).

95. Li, H.; Handsaker, R.; Wysoker, A.; Fennell, T.; Ruan, J.; Homer, N.; Marth, G.; Abecasis, G.; Durbin, R. The Sequence Alignment/Map format and SAMtools. Bioinformatics 2009, 25, 2078-2079. [CrossRef] [PubMed] 
96. Shannon, P.; Markiel, A.; Ozier, O.; Baliga, N.; Wang, J.T.; Ramage, D.; Amin, N.; Schwikowski, B.; Ideker, T. Cytoscape: A Software Environment for Integrated Models of Biomolecular Interaction Networks. Genome Res. 2003, 13, 2498-2504. [CrossRef] [PubMed]

97. R Core Team. R: A Language and Environment for Statistical Computing; R Foundation for Statistical Computing: Vienna, Austria, 2019. Available online: https:/ / www.r-project.org/ (accessed on 12 October 2021).

98. Kearse, M.; Moir, R.; Wilson, A.; Stones-Havas, S.; Cheung, M.; Sturrock, S.; Buxton, S.; Cooper, A.; Markowitz, S.; Duran, C.; et al. Geneious Basic: An integrated and extendable desktop software platform for the organization and analysis of sequence data. Bioinformatics 2012, 28, 1647-1649. [CrossRef] 